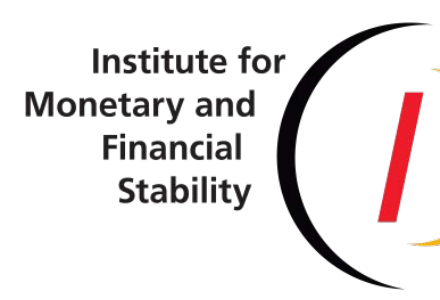

TIZIANA ASSENZA, ALBERTO CARDACI, DOMENICO DELLI GATTI

\author{
Perceived wealth, cognitive sophistication \\ and behavioral inattention
}

Institute for Monetary and Financial Stability

GOETHE UNIVERSITY FRANKFURT

Working PAPER SERIES No. 135 (2019) 
This Working Paper is issued under the auspices of the Institute for Monetary and Financial Stability (IMFS). Any opinions expressed here are those of the author(s) and not those of the IMFS. Research disseminated by the IMFS may include views on policy, but the IMFS itself takes no institutional policy positions.

The IMFS aims at raising public awareness of the importance of monetary and financial stability. Its main objective is the implementation of the "Project Monetary and Financial Stability" that is supported by the Foundation of Monetary and Financial Stability. The foundation was established on January 1, 2002 by federal law. Its endowment funds come from the sale of 1 DM gold coins in 2001 that were issued at the occasion of the euro cash introduction in memory of the D-Mark.

The IMFS Working Papers often represent preliminary or incomplete work, circulated to encourage discussion and comment. Citation and use of such a paper should take account of its provisional character.

\section{Institute for Monetary and Financial Stability}

Goethe University Frankfurt

House of Finance

Theodor-W.-Adorno-Platz 3

D-60629 Frankfurt am Main

www.imfs-frankfurt.de I info@imfs-frankfurt.de 


\title{
Perceived wealth, cognitive sophistication and behavioral inattention*
}

\author{
Tiziana Assenza ${ }^{1}$, Alberto Cardaci ${ }^{2}$, and Domenico Delli Gatti ${ }^{3,4}$ \\ ${ }^{1}$ Toulouse School of Economics, University of Toulouse Capitole \\ ${ }^{2}$ Goethe University Frankfurt \\ ${ }^{3}$ Complexity Lab in Economics, Università Cattolica del Sacro Cuore \\ ${ }^{4}$ CESifo Group Munich, Germany
}

\begin{abstract}
By means of a laboratory experiment, we show that, contrary to standard consumer theory, financially equivalent balance sheet profiles may be perceived as non fungible in a controlled frictionless environment with no probabilistic attributes. A large majority of subjects indeed have a bias in the perception of wealth, such that balance sheet composition matters: for a given net worth with values of assets and debt that are financially certain and risk-free, a greater asset-debt ratio implies greater perceived wealth. The predominance of this bias is explained by low cognitive sophistication and great inattention. Moreover, biased subjects are less patient, less debt averse, more likely to increase spending out of unexpected gains and report greater propensities to consume. A standard optimal consumption choice model, enriched with a rational but inattentive agent à la Gabaix (2014, 2019), aligns our key experimental findings.
\end{abstract}

JEL: C91, D91, G41, G51

Keywords: perceived wealth, cognitive sophistication, behavioral inattention, laboratory experiment, household debt, consumption

\footnotetext{
${ }^{*}$ We are grateful to Daron Acemoglu, Edouard Challe, Fabrice Collard, John Duffy, Roger Farmer, Xavier Gabaix, Alessandro Gobbi, Jakob Grazzini, Michel Habib, Michael Haliassos, Laurence Kotlikoff, Per Krusell, Guilherme Lichand, Domenico Massaro, Marti Mestieri, Collin Raymond, Jean Charles Rochet, Eldar Shafir, Matthew Shapiro, Jean Tirole and numerous seminar and conference participants for helpful comments and suggestions. Tiziana Assenza acknowledges funding from ANR under grant ANR-17-EURE-0010 (Investissements d'Avenir program). This work is part of the project Cognitive biases, perceived wealth and macroeconomic instability for which Alberto Cardaci has received financial support from the AXA Research Fund.
} 


\section{Introduction}

Can people have a wrong perception of how wealthy they are? Abundant theoretical and empirical studies in economics and psychology show that individuals often struggle (and frequently fail) to form a correct perception of how much they are worth in terms of income or net wealth, both in absolute terms and relative to others (Bénabou and Tirole, 2006; Chambers et al., 2014; Cruces et al., 2013; Dawtry et al., 2015; Gasiorowska, 2014; Hauser and Norton, 2017; Loughnan et al., 2011; Norton and Ariely, 2011; Ravallion and Lokshin, 2002). Wealth misperception i.e. a deviation of perceived individual wealth from actual net worth - may be due to various reasons, from money illusion, which leads individuals to define preferences in terms of nominal magnitudes (Fehr and Tyran, 2014; Fisher, 1928; Miao and Xie, 2013; Shafir et al., 1997), to the existence of heterogeneous beliefs over the future state of the world in the presence of a market for bets (Guzman and Stiglitz, 2016a,b).

Can wealth misperception arise also in the absence of "frictions" such as probabilistic attributes, money illusion, uncertainty or heterogeneous beliefs? If yes, what lies at the root of misperception in a frictionless environment? This is the focus of this paper.

In order to address these questions we proceed in four stages. First, by means of a laboratory experiment, we test whether perceived wealth may deviate from actual net wealth in a controlled environment with no frictions related to probabilistic components, such that financial values are risk free and unaffected by price variations. Secondly, having found evidence of such a deviation, we evaluate different explanations related to individual characteristics, such as risk preferences, financial literacy and experience, cognitive abilities and attention capacity. Third, by means of a survey, we assess the importance of wealth misperception in our controlled environment by evaluating whether it has any predictive power over individual attitudes towards consumption and debt. Finally, we show that a standard optimal consumption choice model, enriched with a behaviorally inattentive agent à la Gabaix (2014, 2019), aligns our key experimental findings and can contribute to shed some light on the excess consumption smoothing puzzle in household finance (Beshears et al., 2018; Deaton, 2008; Gorbachev, 2011; Jappelli and Pistaferri, 2010).

The contribution of this paper to the existing literature is, therefore, twofold. First, we find that wealth misperception arises even in a frictionless enviroment. Secondly, we show that wealth misperception is related to low cognitive abilities and inattention, and that subjects who misperceive wealth have a greater tendency to borrow and spend out of gains.

The experiment consists of different tasks and a survey. Participants are initially instructed on the necessary financial concepts, as well as the distinctive features of the operating context. In the first task, each subject is shown a certain number of pairs of financially equivalent balance sheet profiles that have the same (positive or negative) net worth but different levels of assets and liabilities. Subjects are asked to compare the profiles in each pair based on their perceived financial soundness, a proxy for perceived wealth. Notice that the experimental environment is free of any distortions because both assets and liabilities are non-interest bearing, financially certain, risk-free and predetermined. Hence, a rational unbiased subject should perceive the profiles as fungible and associate the same level of perceived wealth to both of them. Standard consumer theory indeed predicts that a rational individual treats money as fungible (Hastings and Shapiro, 2013; Thaler, 1990) - a dollar is a dollar (Hastings and Shapiro, 2013) - and, consequently, given wealth, the composition of the balance sheet is irrelevant for perceptions, preferences and choices (Abeler and Marklein, 2017; Modigliani and Miller, 1958; Thaler, 1990). This represents the theoretical benchmark of our study. The analysis of our experimental results by means of Bayesian techniques points to a substantial departure from the benchmark. In fact, we find that the probability that a subject is unbiased - stating that the two profiles in each pair are financially equivalent - is markedly lower than the probability that a subject is biased indicating that one profile is financially superior. The fraction of biased subjects is estimated to be greater than $80 \%$. Furthermore, of all possible answers, the one associated with the largest 
estimated probability (roughly 70\%) is the one corresponding to a preference for profiles with greater asset-debt ratios, both when net worth is positive and when is negative. We label this prevailing pattern as the leverage bias.

To gain a deeper understanding of the relationship between perceived wealth and balance sheet composition, we introduce a second task. In this case, subjects have to simultaneously evaluate the perceived financial soundness of ten financially equivalent balance sheet profiles with the same net worth but different levels of assets and liabilities. Evaluation occurs by assigning a grade from 1 to 10 to each profile. We also instruct subjects on the possibility to assign any equal grade to all profiles that they consider financially equivalent. We find a strong positive correlation between the asset-debt ratios of the profiles and the average grades assigned by subjects with the leverage bias, which confirms the tendency to depart from the unbiased rational benchmark. ${ }^{1}$

By means of incentivized tasks and a set of questions, we collect information on individual characteristics that allows to investigate why subjects perceive financially equivalent balance sheet profiles as non fungible. We mainly evaluate three explanations: risk preferences, financial literacy and experience, cognitive sophistication and attention capacity.

We first elicit individual risk preferences by means of a standard multiple price list method structured as a game of 10 rounds (Holt and Laury, 2002).

To test the role of financial education we carefully design the selection process of the participants in the experiment in order to isolate those with a financial training from the rest. We also ask information on credit-card ownership as a proxy for the level of financial experience of the subjects. ${ }^{2}$

Finally, to measure agents' cognitive sophistication, we introduce an incentivized version of the Cognitive Reflection Test (CRT) developed by Frederick (2005). CRT evaluates the ability of the subjects to override their impulsive and inattentive answer that is wrong, in favor of the attentive and consciously deliberated correct answer. To adopt the categorization of Dual Process Theory (Kahneman, 2003a,b, 2011; Stanovich and West, 2003), CRT assesses the (im)balance between the attentive effort associated with analytical and deliberate thinking (socalled System 2) - which indeed takes up a great deal of attention (Toplak et al., 2014) - and automatic thinking (System 1), which consumes little or no attentional resources (Kihlstrom, 1987; Moritz et al., 2014).

Explanations related to risk preferences or financial literacy and experience are not supported by our results. A series of Bayesian regressions indeed show that the presence of the leverage bias has a much larger probability of being predicted by individual scores in CRT. In fact, subjects with the leverage bias perform significantly worse in CRT compared to unbiased subjects. Therefore, our main findings suggest that the tendency to perceive financially equivalent balance sheet profiles as non fungible and associate greater perceived wealth to profiles with higher values of the asset-debt ratio is correlated with a predominance of System 1 thinking.

At the end of the experiment, we include a small survey to evaluate the relationship between the leverage bias, wealth misperception and consumption and borrowing behavior. Our survey draws on the "reported preference" approach (Fuster et al., 2018; Parker and Souleles, 2017), which relies on reported changes in borrowing or spending in hypothetical scenarios. In

\footnotetext{
${ }^{1}$ A scrupulous reader might note that a preference for greater asset-debt ratios implies choosing profiles with lower levels of assets and debt, when net worth is positive, and higher assets and debt when net worth is negative. This reversal of preferences may seem analogous to the findings of prospect theory and decision-making in risky environments (Kahneman and Tversky, 1979), which suggests a switch from risk aversion to risk seeking when the value of a gamble changes from positive to negative (Frederick, 2005). In line with this, the reader might relate the observed pattern of choices to a change from debt aversion to debt seeking when the sign of net worth changes. However, our set-up is risk-free and has no probabilistic properties. Moreover, as reported later in the paper, we find that biased subjects are generally less debt averse and more prone to borrow for consumption.

${ }^{2}$ Credit or debit card ownership is often associated with greater user experience and lower cost of fees (Agarwal and Mazumder, 2013) and, as such, it has been used as a proxy for financial sophistication and experience in several empirical analyses (see, e.g., Attanasio et al., 2002; Stango and Zinman, 2009).
} 
addition to a standard set of socio-demographic questions, our survey includes questions about personal attitudes towards credit-financed spending, impatience and saving type, the response to a hypothetical financial emergency, and the likelihood to increase spending out of unexpected gains.

We find that the leverage bias has a strong predictive power over attitudes towards consumption and debt. Biased subjects are generally more comfortable with the use of credit to finance consumption and deal with financial emergencies. Moreover, we find that subjects with the leverage bias are also more likely to borrow for consumption under financial profiles characterized by higher asset-debt ratios, while unbiased subjects make borrowing decisions that are neutral to the composition of the balance sheet. Finally, biased subjects report a greater likelihood to increase consumption out of unexpected gains, as well as larger average propensities to consume, compared to unbiased subjects.

In the last part of the paper, we build a two-period optimal consumption choice model that explains our key experimental results. The model features two types af agents: (i) a standard rational agent representing the unbiased subject and (ii) a behavioral agent à la Gabaix (2014, 2019) who has a wrong perception of wealth due to inattention and low cognitive sophistication. The behavioral agent intends to capture the biased subject in our experiment, characterized by a predominance of System 1 over System 2. We show that, in line with our experimental results, the model produces a greater marginal propensity to consume and lower debt aversion of the biased agent compared to the rational benchmark. Our model also contributes to shed some light on the excess consumption smoothing puzzle (Beshears et al., 2018; Gorbachev, 2011; Jappelli and Pistaferri, 2010). While we do not provide quantitative estimates, we show that our model produces a pattern of consumption characterized by larger volatility and lower smoothing, relative to the standard benchmark of existing models.

This paper adds to the literature that focuses on the determinants of the formation of erroneous wealth perception and its implications for financial decisions. Compared to possible explanations that rely on heterogeneity in beliefs, uncertainty and probabilistic components (Fehr and Tyran, 2014; Fisher, 1928; Guzman and Stiglitz, 2016a,b; Miao and Xie, 2013; Shafir et al., 1997), we map the objective reality of actual wealth into the subjective perception of it in a controlled frictionless set-up. In particular, we provide evidence that people do not perceive financially equivalent balance sheet profiles as fungible, even in an environment where values are risk-free and unaffected by price variations. We thus support the literature that questions the fungibility of money and the irrelevance of the composition of wealth for economic choices (Thaler, 1999; Tversky and Kahneman, 1981). Related findings (Abeler and Marklein, 2017; Hastings and Shapiro, 2013; Kooreman, 2000) indeed reveal the violation of fungibility in the realm of consumption decisions and show that these are not based on net wealth alone.

Second, our experimental findings and theoretical model, which are grounded in Dual Process Theory (Kahneman, 2003a,b, 2011; Stanovich and West, 2003) and theories of behavioral inattention (Gabaix, 2014, 2019), contribute also to the literature that relates financial mistakes and non-optimal decisions to low cognitive abilities and inattention (Agarwal and Mazumder, 2013; Andersen et al., 2014; Banks and Oldfield, 2007; Gerardi et al., 2013; Sicherman et al., 2016; Stango and Zinman, 2014). To the best of our knowledge, ours is the first work providing experimental evidence that ties cognitive sophistication and attention capacity to the perception of wealth and, consequently, individual decisions to consume and borrow.

The rest of this paper proceeds as follows. Section 2 provides an overview of the laboratory experiment: it introduces the main hypotheses, the experimental design and procedures and it presents the key findings. Section 3 introduces the model of behavioral inattention. Section 4 concludes. 


\section{Experiment overview}

Our experiment is divided in three parts, with five tasks in total:

1. The first part tests whether, for a given net worth, the perception of wealth varies as a function of the composition of the balance sheet in a context that is risk-free and has no probabilistic properties. This part is composed of the Profile Evaluation Task (PET) and the Profile Grading Task (PGT).

2. In the second part we evaluate cognitive abilities by means of an incentivized version of the Cognitive Reflection Test (CRT) developed by Frederick (2005). We also elicit riskaversion via the multiple price list method introduced by Holt and Laury (2002) (RISK henceforth). Finally we evaluate financial sophistication by means of a simple question on credit/debit card ownership.

3. The third part includes a small survey with a set of questions measuring impatience, debt aversion, the propensity to take on debt for consumption and to spend out of unexpected gains.

The experiment was designed using Otree (Chen et al., 2016). A pilot version on the first two parts was run in April 2018. The full experiment was run in September 2018 with the participation of 93 students from Università Cattolica del Sacro Cuore in Milan (Italy). Two groups of students participated in our experiment: one was composed of students randomly selected from those enrolled in any academic program of the Faculty of Economics, conditional on having passed four courses in accounting, finance and business with a grade of at least $27 / 30$; the other group was composed of students randomly selected from other academic programs, with no economics or finance background. Such distinction between the two groups is used as a proxy for financial education.

Subjects were paid a $€ 5$ show-up fee, plus an amount related to their performance in the incentivized tasks (i.e. CRT and RISK). The average gain was $€ 8.87$ (std. 2.82).

\subsection{Perceived wealth and balance sheet composition}

In this subsection we describe PET and PGT. For both tasks, we start by introducing the main assumptions; we then illustrate the design and the procedures; finally, we discuss the results.

\subsubsection{Profile Evaluation Task}

PET allows to understand whether, in a frictionless context - i.e. a context in which financial values are risk-free, non-interest bearing, perfectly observed and unaffected by price variations financially equivalent profiles may be associated with different levels of perceived wealth $(P W)$, based on their balance sheet composition. Formally, PET tests the following hypothesis:

Hypothesis 1: For a given pair of financially equivalent balance-sheet profiles $(i=a, b)$, with identical net worth but different values of assets and debt that are financially certain, non-interest bearing and risk-free, subjects will choose a over $b(a \succ b)$ or $b$ over $a(a \prec b)$.

In order to test Hypothesis 1, participants in PET are shown 10 pairs of hypothetical financial profiles with identical net worth but different levels of assets and debt. Subjects see 10 pairs in total: 5 with positive net worth and 5 with negative net worth. The order of the pairs presented to participants is randomized at the individual level. In each pair we distinguish the profile with a higher asset-debt ratio - High Ratio Profile (HRP) - and the profile with a lower asset-debt ratio - Low Ratio Profile (LRP). For each pair, each subject chooses the profile that 
she considers financially superior (either HRP or LRP), or she can state that the two profiles as financially equivalent (Equivalent Profiles, EQP). Figure 1 shows the interface of PET. ${ }^{3}$

Figure 1: Interface of PET.

\begin{tabular}{cc}
\multicolumn{2}{c}{ Mr. A } \\
\hline Attività & $32.000 €$ \\
Passività & $7.350 €$ \\
\hline Saldo & $24.650 €$
\end{tabular}

\begin{tabular}{cc}
\multicolumn{2}{c}{ Mr. B } \\
\hline Attività & $74.800 €$ \\
Passività & $50.150 €$ \\
\hline Saldo & $24.650 €$
\end{tabular}

\author{
Questa è la coppia 7. \\ Indica quale dei due profili ritieni finanziariamente migliore: \\ Mr. A \\ Mr. B \\ Sono equivalenti
}

Successivo

The set-up introduced in PET is similar to the one first used in Sussman and Shafir (2012) and later adopted in Sussman (2017) and de Langhe and Puntoni (2015). However, we modify this set-up with some additional options and controls that avert inappropriate considerations about factors that are external to our framework. For example, compared to Sussman and Shafir (2012), Sussman (2017) and de Langhe and Puntoni (2015), the introduction of the EQP option allows for the identification of unbiased subjects, who perceive the two profiles in each pair as fungible. Moreover, before performing the task, all subjects are provided with essential definitions of the financial concepts involved in PET and a set of control questions testing the full understanding of the instructions. Differently from Sussman and O'Brien (2016), Sussman and Shafir (2012) and de Langhe and Puntoni (2015), the design of our experiment rules out any disturbances related to potential risk considerations or unwanted inference about the profiles in each pair. First, in order to avoid general risk considerations, or expectations about asset (or debt) value fluctuations, we state explicitly that all values shown in this task are certain and realized in the past. We also inform subjects that all values of assets and debt are non-interest bearing. In order to avoid evaluations based on possible inference on labor market positions, we point out that all profiles in each pair are associated with the same constant monthly income. Finally, subjects are also told that all profiles correspond to people who can access the credit market at the same conditions. This clarifies the risk-free, time-invariant and financially certain framework of our experiment. It also represents a setup in which the interest rate plays no role from a rational standpoint, as values are non-interest bearing, while the interest rate on the credit market does not depend on the balance sheet composition.

Based on our set-up, in each pair, subjects can have a preference for HRP (the high assetdebt ratio profile), LRP (the low asset-debt ratio profile) or EQP (stating that the two profiles are equivalent). For a given sign of the net worth, if consistent, a subject would make the same choice across all pairs; if inconsistent, we would not observe any regularity, as the subject would switch multiple times from an answer to the other (e.g. from LRP in one pair with a given net worth sign, to HRP or EQP in another pair with the same net worth sign). In order to discard such inconsistent subjects, we introduce the following consistency threshold: we will consider

\footnotetext{
${ }^{3}$ The experiment was run in Italian. See Appendix A for a copy of the instructions translated in English.
} 
only the subsample of participants who, for a given sign of the net worth, make the same type of choice in at least $80 \%$ of the pairs. Table 1 shows the 9 possible consistent patterns that may emerge in PET. For example, pattern 1 corresponds to an individual choosing LRP in (at least $80 \%$ of) the pairs with positive net worth and in (at least $80 \%$ of) the pairs with negative net worth. Analogously, pattern 2 identifies a subject with a preference for LRP in (at least $80 \%$ of) the pairs with positive net worth and HRP in (at least $80 \%$ of) the pairs with negative net worth.

Table 1

Patterns of choices in PET

\begin{tabular}{c|ccccccccc}
\hline \hline NW & 1 & 2 & 3 & 4 & 5 & 6 & 7 & 8 & 9 \\
\hline$>0$ & LRP & LRP & LRP & HRP & HRP & HRP & EQP & EQP & EQP \\
$<0$ & LRP & HRP & EQP & LRP & HRP & EQP & LRP & HRP & EQP \\
\hline Distribution & 0 & $2.74 \%$ & 0 & 0 & $78.08 \%$ & $4.11 \%$ & 0 & 0 & $15.07 \%$ \\
\hline \hline
\end{tabular}

LRP: low asset-debt ratio profile; HRP: high asset-debt ratio profile; EQP: equivalent. Percentage values indicate the distribution of subjects across the different patterns.

Results from PET. Based on Table 1, we introduce the following classification:

- Unbiased subjects: all subjects stating that the two profiles are equivalent (EQP) both in pairs with positive net worth and in pairs with negative net worth. This corresponds to pattern 9 in Table 1 and it characterizes all individuals whose perception of wealth is invariant to the composition of the balance sheet. These individuals perceive the two profiles in each pair as fungible.

- Biased subjects: all subjects with a preference for one of the two profiles, both in pairs with positive net worth and in pairs with negative net worth. This corresponds to patterns 1, 2, 4 and 5. Biased subjects have a level of perceived wealth that, for a given (positive or negative) net worth, changes based on the level of assets and debt. These individuals perceive the two profiles in each pair as non-fungible. Patterns 3, 6, 7 and 8 correspond to subjects who are partially biased: they perceive financial profiles as different only when net worth is either positive or negative.

Based on our consistency threshold, our sample includes 73 subjects ( $78.49 \%$ of participating people): ${ }^{4} 80.82 \%$ of them are fully biased, i.e., they have a preference for one of the two profiles both when net worth is positive and when it is negative (patterns 2 and 5 in Table 1); $4.11 \%$ are partially biased, having a preference for one of the two profiles only for pairs with positive net worth (pattern 6); $15.07 \%$ are unbiased as they state that the financial profiles are equivalent both in pairs with positive net worth and in pairs with negative net worth (pattern 9). This is a first indication that a large majority of the sample is composed of subjects who have a bias in the perception of wealth, such that, for a given net worth, their level of perceived wealth depends on the composition of the balance sheet, even if the context is frictionless. In addition, $96.61 \%$ of biased subjects choose HRP both when net worth is negative and when it is positive (pattern 5 in Table 1). We label this pattern as the leverage bias. The predominance of this type of preference suggests the existence of a positive relationship between the asset-debt ratio and the level of perceived wealth, for a given net worth.

We want to evaluate the probability associated with each of the possible patterns of answers in our sample. To this purpose, we run an intercept-only logistic regression in order to estimate

\footnotetext{
${ }^{4}$ There is a trivially inverse relationship between the consistency threshold and the sample dimension: the percentage of consistent subjects would be $51.61 \%$ with $100 \%$ consistency, while increasing to $95.7 \%$ with $60 \%$ consistency.
} 
the predicted probability associated with the four possible outcomes: unbiased (pattern 9), leverage bias (pattern 5), other forms of bias (pattern 2) and partial bias (pattern 6). Given the relatively small sample dimension, we proceed by means of Bayesian techniques. In particular, we impose a $N(0,1)$ neutral prior on the coefficients of the four outcomes. We use Markov Chain Monte Carlo (MCMC) sampling with the Metropolis-Hastings algorithm (Hastings, 1970; Metropolis et al., 1953) and a sample size equal to 100000.

Table 2

Predicted probabilities

\begin{tabular}{cc}
\hline \hline Unbiased & $16.81 \%$ \\
Leverage bias & $70.49 \%$ \\
Other bias & $5.79 \%$ \\
Partial bias & $6.91 \%$ \\
\hline \hline
\end{tabular}

Random-walk Metropolis-Hastings sampling with 100000 MCMC sample size; acceptance rate: .4398; average efficiency rate: .2195 .

Prior $N(0,1)$ on all model coefficients.

Table 2 shows the predicted probabilities of the four outcomes: while being unbiased is associated with a probability of $16.81 \%$, the estimated predicted probability of being biased is $83.19 \%$ overall. ${ }^{5}$ In particular, the probability associated with the existence of the leverage bias is $70.49 \%$, while the other two patterns have significantly lower probabilities. This result supports our hypothesis, in that the probability that subjects have different perceptions of financially equivalent profiles is much larger than the probability that subjects are unbiased and perceive the profiles as fungible. In particular, the leverage bias emerges as the predominant pattern: for a given net worth, the large majority of subjects have greater perceived wealth for higher values of the asset-debt ratio, both when net worth is positive and when is negative. ${ }^{6}$

\subsubsection{Profile Grading Task}

PGT allows to check the consistency of the answers provided by subjects in PET when the evaluation process involves more than two financially equivalent profiles. In addition, the task tests for the presence of a specific quantitative relationship between perceived wealth and the balance sheet composition. In fact, subjects are simultaneously shown 10 financial profiles with equal net worth but different levels of assets and debt. The task consists in grading the financial soundness of each profile on a scale from 1 (worst off) to 10 (best off). Subjects can assign any grade in this range, as the evaluation occurs by moving a pointer on a bar that corresponds to the continuous 1-10 interval. ${ }^{7}$ In order to identify unbiased individuals, participants are also told that they may assign the same grade to all the profiles that they consider financially equivalent. Therefore, PGT tests the following hypothesis:

Hypothesis 2: For a given set of profiles $(i=1,2, \ldots, 10)$ with identical net worth but different values of assets and debt, biased subjects will assign different grades $\left(g_{i}\right)$ to all profiles, such that $g_{1} \neq g_{2} \neq \ldots \neq g_{10}$.

\footnotetext{
${ }^{5}$ Posterior means and high-posterior density intervals are reported in Appendix B.

${ }^{6}$ To check for possible explanations related to the framing of the task or computational difficulties, we include two pairs, in which the value of one, between assets and debt, is hidden in both profiles. Also in these pairs all unbiased subjects perceive the two profiles as fungible, while only one biased subject is inconsistent with previous answers. This suggests that the reported pattern of preferences is robust to the framing of the problem and computational difficulties.

${ }^{7}$ The use of the bar allows to account for the so-called digit preference, which is the tendency to round numbers to agreeable digits (Camarda et al., 2017).
} 
PGT is repeated twice, once with 10 profiles with positive net worth and once with 10 profiles with negative net worth. Figure 2 shows the interface of PGT with some of the profiles shown to subjects. Before performing the task, subjects are once again provided with the financial definitions of assets, debt and net worth and with the set of information shown in PET, so as to provide a set up that is financially certain, risk-free and unaffected by price variations. Based on the results from PET, we focus the rest of our analysis on the comparison between subjects with the leverage bias (pattern 5 in Table 1) and those who are unbiased (pattern 9 in Table $1)$.

Figure 2: Interface of PGT.

\begin{tabular}{cc}
\multicolumn{2}{c}{ Profilo 1} \\
\hline Attività & $54.000 €$ \\
Passività & $14.800 €$ \\
\hline Saldo & $39.200 €$ \\
& \\
\multicolumn{2}{c}{ Profilo 2 } \\
\hline Attività & $123.000 €$ \\
Passività & $83.800 €$ \\
\hline Saldo & $39.200 €$ \\
& \\
Profilo 3 \\
\hline Attività & $41.000 €$ \\
Passività & $1.800 €$ \\
\hline Saldo & $39.200 €$
\end{tabular}

Voto profilo 1:

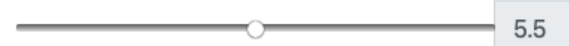

Voto profilo 2:

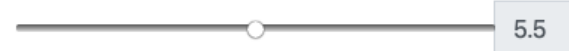

Voto profilo 3:

Results from PGT. We find that all unbiased subjects assign equal grades to all profiles, both when net worth is positive and when is negative, thus being $100 \%$ consistent with the answers provided in PET. This confirms that their perception of wealth does not change as a function of the composition of the balance sheet, for a given net worth. On the contrary, all subjects with the leverage bias assign different grades to the 10 financially equivalent profiles, both when net worth is positive and when is negative.

Table 3

Bayesian OLS regression of average grades over asset-debt ratio

\begin{tabular}{ccc}
\hline \hline & Positive Net Worth & Negative Net Worth \\
\hline Mean & .5356 & .1047 \\
Std. dev. & .3766 & .3163 \\
$68 \%$ HPD & {$[.1649 .8984]$} & {$[-.1998 .4314]$} \\
\hline \hline
\end{tabular}

Bayesian OLS regression of average grades over asset-debt ratio

Prior $N(0,1)$ on all model coefficients. Random-walk Metropolis-Hastings sampling with 100000 MCMC sample size. Positive net worth, acceptance rate: 0.3789; average efficiency rate: 0.0806 . Negative net worth, acceptance rate: 0.4104 ; average efficiency rate: 0.0897 .

Values in parenthesis are $68 \%$ highest posterior density intervals.

Table 3 shows the results from a Bayesian linear regression of average grades assigned by subjects with the leverage bias on the asset-debt ratio of the profiles in PGT, in both the positive and the negative net worth case. The informative $N(0,1)$ prior for the coefficients of the asset-debt ratio assumes neutrality and the absence of any relation between the two variables. Nonetheless, results support the existence of a positive relationship between perceived wealth, 
proxied by the average grade in PGT, and the asset-debt ratio of the profiles shown to subjects: an increase in the ratio by one results in an increase in the average grade of roughly .54, for a given positive net worth, and .1, in the negative net worth case.

Summing up the results from PET and PGT, we find evidence of a deviation from standard consumer theory: the vast majority of our sample is composed by biased subjects who, absent any friction related to probabilistic attributes, perceive financially equivalent profiles as nonfungible and have a level of perceived wealth that depends on the balance sheet composition. In particular, for a given net worth, these individuals have a clear preference for balance sheet profiles with higher values of the asset-debt ratio. Even by imposing a neutral prior, our Bayesian estimation highlights the strength of the relationship between the asset-debt ratio and perceived wealth. Given the absence of any frictions, subjects' answers seem hardly attributable to rational considerations related to risk, interest payments or gains, or financial uncertainty. Results from PET and PGT, therefore, provide suggestive evidence in favor of a behavioral interpretation of the leverage bias, which seems in fact a cognitive bias. We test this and alternative explanations in the next section.

\subsection{Interpretations}

First, we test whether the presence of the leverage bias relates to risk attitudes. In particular, we elicit individual risk preferences by means of the multiple price list method introduced by Holt and Laury (2002). This task - RISK - is structured as a game composed of 10 rounds (Figure 3). In each round, participants have to choose between two risky options, A and B, each giving the possibility to participate in a lottery. RISK is an incentivized task: the outcome of one of the 10 chosen lotteries is randomly selected as the individual pay-off at the end of the game.

Figure 3: Lotteries in RISK.

Opzione A

Opzione B

\begin{tabular}{|c|cc|cc|cc|cc|}
\hline & Probabilità & Vincita & Probabilità & Vincita & Probabilità & Vincita & Probabilità & Vincita \\
\cline { 2 - 8 } 1 & $1 / 10$ & $2,00 €$ & $9 / 10$ & $1,60 €$ & $1 / 10$ & $3,85 €$ & $9 / 10$ & $0,10 €$ \\
2 & $2 / 10$ & $2,00 €$ & $8 / 10$ & $1,60 €$ & $2 / 10$ & $3,85 €$ & $8 / 10$ & $0,10 €$ \\
3 & $3 / 10$ & $2,00 €$ & $7 / 10$ & $1,60 €$ & $3 / 10$ & $3,85 €$ & $7 / 10$ & $0,10 €$ \\
4 & $4 / 10$ & $2,00 €$ & $6 / 10$ & $1,60 €$ & $4 / 10$ & $3,85 €$ & $6 / 10$ & $0,10 €$ \\
5 & $5 / 10$ & $2,00 €$ & $5 / 10$ & $1,60 €$ & $5 / 10$ & $3,85 €$ & $5 / 10$ & $0,10 €$ \\
6 & $6 / 10$ & $2,00 €$ & $4 / 10$ & $1,60 €$ & $6 / 10$ & $3,85 €$ & $4 / 10$ & $0,10 €$ \\
7 & $7 / 10$ & $2,00 €$ & $3 / 10$ & $1,60 €$ & $7 / 10$ & $3,85 €$ & $3 / 10$ & $0,10 €$ \\
8 & $8 / 10$ & $2,00 €$ & $2 / 10$ & $1,60 €$ & $8 / 10$ & $3,85 €$ & $2 / 10$ & $0,10 €$ \\
9 & $9 / 10$ & $2,00 €$ & $1 / 10$ & $1,60 €$ & $9 / 10$ & $3,85 €$ & $1 / 10$ & $0,10 €$ \\
10 & $10 / 10$ & $2,00 €$ & $0 / 10$ & $1,60 €$ & $10 / 10$ & $3,85 €$ & $0 / 10$ & $0,10 €$ \\
\hline
\end{tabular}

We also want to verify whether subjects that are more financially experienced or literate are less likely to have biased perceptions of wealth. To this purpose, we evaluate subjects' familiarity with basic financial tools by means of the following question, taken from the 2016 Survey of Consumer Finances (SCF): "Do you have at least one credit or debit card?". Credit or debit card ownership and usage has been used as a proxy for financial sophistication in several empirical analyses (see, e.g., Attanasio et al., 2002; Stango and Zinman, 2009). In fact, credit card ownership is often associated with learning mechanisms that increase user experience and reduce the cost of fees (Agarwal and Mazumder, 2013). Also financial literacy is widely recognized as a factor that affects the quality of individual financial decision-making 
(Lusardi and Tufano, 2015; van Rooij et al., 2011). We therefore exploit the different university background of the students in our experiment as a proxy for their financial literacy. We consider as financially educated all the students randomly selected from the faculty of Economics and having passed four courses in finance and accounting with a grade of at least $27 / 30$. All the students who were randomly selected from non-economics courses are labeled as financially uneducated. $^{8}$

Finally, we investigate whether the presence of the leverage bias relates to individual cognitive abilities. To this purpose, we employ an incentivized version of the Cognitive Reflection Test first proposed by Frederick (2005). CRT is based on three questions that test the ability of the subject to override the instinctive responses that are wrong, in favor of the more sophisticated correct answers (Bosch-Rosa et al., 2018). In other words, the test assesses the ability of the subject to switch from the fast, intuitive and inattentive thinking associated with System 1, to the attentive, logical and consciously deliberated type of thinking of System 2, as described in Dual Process Theory (Kahneman, 2003a,b, 2011; Stanovich and West, 2003). In fact, CRT is a powerful test and a significant predictor of cognitive abilities, rational thinking and working memory (Toplak et al., 2011).

CRT is composed of the following three questions:

- A bat and a ball cost $€ 1.10$. The bat costs $€ 1$ more than the ball. How much does the ball cost?

- It takes 5 machines 5 minutes to make 5 widgets. How long would it take 100 machines to make 100 widgets?

- In a lake, there is a patch of lily pads. Every day, the patch doubles in size. If it takes 48 days for the patch to cover the entire lake, how long would it take for the patch to cover half of the lake?

Subjects have 2 minutes and 30 seconds to answer each question. The agent gets one point for each correct answer, hence the minimum score is 0 and the maximum is 3 . We incentivize effort and attention by remunerating the subject with $€ 2$ for each point. Therefore, the minimum payoff is $€ 0$ and the maximum is $€ 6$.

\subsubsection{Results}

In Table 4 we report the marginal effects from a series of Bayesian logistic regressions of a dummy equal to 1 for the leverage bias on four variables: risk aversion, financial sophistication, financial education and CRT score. In all regressions, we assume a $N(0,1)$ prior for model coefficients, thus making a neutral assumption on the predictive power of each of the four individual characteristics. In all regressions we control for age, gender, family size and family education. $^{9}$

Results show that greater cognitive sophistication is negatively correlated with the presence of the leverage bias: when CRT score increases by 1 point, the probability of being biased decreases by roughly 8 percentage points. Also risk aversion is negatively correlated with the bias but the absolute value is substantially smaller. The other two variables are positively correlated with the probability of being biased, but also in this case the value is smaller compared to the absolute value of CRT score.

We want to test which of the four Bayesian logistic regression models in Table 4 is more likely given the observed experimental data. Table 5 reports the posterior probability of each of the models, under the assumption that all of them are equally probable a priori. We find that the

\footnotetext{
${ }^{8}$ The university administration has double checked that students from non-economics courses have never attended any financial course during their studies.

${ }^{9}$ Results with no controls are reported in Appendix B.
} 
Table 4

Behavioral predictors of the leverage bias

\begin{tabular}{ccccc}
\hline \hline & $(1)$ & $(2)$ & $(3)$ & $(4)$ \\
\hline Risk aversion & -.0063 & & & \\
68\% HPDI & {$[-.0142 .0018]$} & & & \\
Financial sophistication & & .0176 & & \\
$68 \%$ HPDI & & {$[-.0221 .0628]$} & & \\
Financial education & & & -0168 & \\
$68 \%$ HPDI & & & {$[-.0155 .0486]$} & -.0823 \\
CRT score & & & $-.0983-.0653]$ \\
$68 \%$ HPDI & Yes & Yes & Yes & Yes \\
Controls & 68 & 68 & 68 & 68 \\
Sample size & & & 68 \\
\hline \hline
\end{tabular}

Marginal effects from a Bayesian logistic regression of a dummy equal to 1 if the subject is biased on (1) number of safe choices in RISK, (2) a dummy equal to 1 if the subject has credit/debit card, (3) a dummy equal to 1 if the subject is financially educated and (4) CRT score. Controls include age, gender dummy, family size and family education level as covariates.

Prior $N(0,1)$ on all model coefficients. Random-walk Metropolis-Hastings sampling with 100000 MCMC sample size.

Values in parentheses are $68 \%$ highest posterior density intervals.

regression model with CRT is substantially more likely given our data, as it is associated with a very large posterior probability of $79.56 \%$. This allows us to conclude that the presence of the leverage bias is most probably related to the level of cognitive sophistication and inattention of the subjects, rather than risk aversion or financial experience (measured either as sophistication or as education).

Table 5: Likelihood of the regression models in Table 4

\begin{tabular}{c|ccc}
\hline \hline & $\log (M L)$ & $P(M)$ & $P(M \mid Y)$ \\
\hline Model 1: Risk aversion & -36.7952 & 0.25 & .0221 \\
Model 2: Financial sophistication & -35.1902 & 0.25 & .1072 \\
Model 3: Financial education & -35.5684 & 0.25 & .0752 \\
Model 4: CRT score & -33.2098 & 0.25 & .7956 \\
\hline \hline
\end{tabular}

$\log (M L)$ : logarithm of marginal likelihood; $P(M)$ : prior probability; $P(M \mid Y)$ : posterior probability.

In fact, results in Table 6 show that unbiased subjects have an average CRT score - i.e. the number of correct answers - equal to 1.81, compared to 1 of the biased group. We also report the within-group distribution of subjects: the percentage of subjects answering 0 correct questions is much larger in the biased group (43.86\%), while the percentage of subjects obtaining the highest score, thus providing all correct answers, is significantly greater within the unbiased group (45.45\%). These results suggest that, relative to unbiased participants, biased subjects are System 1 type of thinkers, with a greater tendency to abide by the spontaneous but wrong answer that first comes to mind when reading the question (Frederick, 2005). ${ }^{10}$ Therefore, the leverage bias seems correlated with lower cognitive sophistication and a tendency to avoid the

\footnotetext{
${ }^{10}$ We also find that CRT score is positively correlated with risk aversion (see Appendix B for all relevant coefficients) - a result that may contribute to the literature on the relationship between cognitive abilities and risk attitudes, which reports mixed evidence. Some works (e.g. Dohmen et al., 2010) find greater willingness to take risk in subjects with greater scores in widely used IQ tests; others, like Andersson et al. (2016), generate both
} 
attentive effort associated with the deliberate thinking of System 2 - which indeed takes up a great deal of attention (Toplak et al., 2014) - in favor of an intuitive and automatic type of thinking, which instead consumes little or no attentional resources (Kihlstrom, 1987; Moritz et al., 2014). In general, the literature in psychology highlights the existence of a significantly positive correlation between a variety of measures of individual cognitive abilities and attention of different types (see, among others, Allred et al., 2016; Aschersleben et al., 2008; Barrett et al., 2004; Ben-Shakhar and Sheffer, 2001; Dukas, 2004). In fact, attentional neglects can often explain the poor performance in cognitive sophistication tasks (Allred et al., 2016; Dukas, 2004).

Table 6

Scores in CRT

\begin{tabular}{cccccc}
\hline \hline & Average score & \multicolumn{4}{c}{ Correct answers } \\
& & 0 & 1 & 2 & 3 \\
\hline \multirow{2}{*}{ Biased } & 1 & $43.86 \%$ & $22.81 \%$ & $22.81 \%$ & $10.53 \%$ \\
\multirow{2}{*}{ Unbiased } & {$[1.05]$} & & & & \\
& 1.81 & $18.18 \%$ & $27.27 \%$ & $9.09 \%$ & $45.45 \%$ \\
\hline \hline
\end{tabular}

Average score (standard error in brackets) and distribution of subjects per correct answers in the Cognitive Reflection Test (CRT).

\subsection{Attitudes towards debt and consumption}

The final part of the experiment consists in a survey to assess the relation between the leverage bias, perceived wealth and subjects' attitudes towards debt and consumption. ${ }^{11}$ For the sake of simplicity we divide the set of questions and the discussion of the results in two groups: first we discuss debt behavior and then we focus on consumption.

\subsubsection{Debt}

In order to have a general evaluation of attitudes towards debt, we rely on a question from the 2016 Survey of Consumer Finances by asking participants whether they think it is a good idea to finance expenses by borrowing. There are three possible answers: "Good idea", "Good in some ways, bad in others" and "Bad idea". Even though this question does not allow to discriminate among different types of debt, it is generally considered a good proxy of personal attitudes towards the use of credit for consumption and it has been used as a measure of debt aversion in other works (see, e.g. Chien and Devaney, 2001; Stango and Zinman, 2009).

We also evaluate subjects' approach to credit when they are faced with financial difficulties. In particular, we introduce the following question that allows to test whether the leverage bias predicts the use of credit when struggling with payments: "If tomorrow you experienced a financial emergency that left you unable to pay all of your bills, how would you deal with it?" The set of possible answers includes "borrow money", "spend out of savings", "postpone payments" and "cut back". Although the answer "borrow money" does not mention a specific type of loan, people who find themselves in a cash crunch often tend to make unsound financial

negative and positive correlations between risk aversion and cognitive abilities, thus concluding that these are related mostly to random decisions rather than risk preferences. Finally, Taylor (2013) shows that the correlation depends on whether risk choices are hypothetical or real. We also find that risk aversion negatively correlates with financial education, adding to the existing evidence that higher financial literacy corresponds to a higher willingness to take risky financial decisions (e.g. Bianchi, 2018; Black et al., 2018).

${ }^{11}$ Appendix A contains the complete list of questions presented in the survey. 
decisions by relying on payday loans and other expensive forms of unsecured credit (Bertrand and Morse, 2011; Mullainathan and Shafir, 2014; Shah et al., 2012).

Finally, we dig deeper into the potential link between the leverage bias and attitudes towards debt, by including a question that draws on the so-called "reported preference" approach (Fuster et al., 2018; Parker and Souleles, 2017). This relies on reported changes in borrowing (or spending) in hypothetical scenarios, elicited by means of survey questions, thus allowing a great amount of flexibility in treatment design (Fuster et al., 2018). In particular, we test the relationship between the leverage bias (and, in turn, perceived wealth) and the likelihood to take on debt for consumption, by presenting participants with a hypothetical situation in which they want to buy a product but, due to the lack of liquid assets, they have to borrow. Subjects are also shown two financial profiles with identical net worth but different balance sheet composition and they are asked to state under which of the two profiles they would be more likely to borrow $€ 500$ to buy the item (a new television). The question is adapted from Sussman and Shafir (2012) but, differently from the original setup, we give subjects the possibility to state that they would borrow under either or neither profile. This allows to identify either aversion to debt (not borrowing under any profile) or neutrality to the balance sheet composition (borrowing under any profile). The question is repeated twice, once with positive net worth and once with negative net worth.

In general, this question is intended to explore the idea that the leverage bias leads to perceptions of wealth that impact the propensity to finance spending by borrowing. If greater perceived wealth were in fact associated with a higher likelihood to take on debt, biased subjects should indicate that they would borrow under the profile with greater asset-debt ratio (HRP). On the contrary, unbiased subjects should be more likely to make a decision that is indifferent to the composition of the balance sheet, given the net worth.

An important remark has to do with the following concern: Do reported preferences have little informative content as to what individuals would do if faced with actual decisions to borrow (or spend)? Fuster et al. (2018) point to the comprehensive analysis carried out by Parker and Souleles (2017) and Parker et al. (2013): the former show that comparing reported consumption responses to hypothetical tax rebates with actual spending responses from past tax rebates, produces very little differences; the latter, found that reported preferences match actual behavior, in that subjects who reported spending their 2008 fiscal stimulus payment did in fact do so. These considerations support the idea that reported preferences in hypothetical scenarios may provide significant indications of individual behavior in actual decision-making contexts.

Table 7

Debt aversion

\begin{tabular}{cccc}
\hline \hline & Averse & Seeker & Neutral \\
\hline Biased & $12.28 \%$ & $43.86 \%$ & $43.86 \%$ \\
Unbiased & $36.36 \%$ & $9.09 \%$ & $54.55 \%$ \\
\hline \hline
\end{tabular}

Averse: spending by borrowing is a bad idea; Seeker: spending by borrowing is a good idea; Neutral: spending by borrowing is good in some ways, bad in others.

Findings on general attitudes towards debt. While a substantial share of both biased and unbiased subjects report that spending by borrowing is neither good nor bad, subjects with the leverage bias seem more comfortable with the idea of debt-financed consumption. Table 7 indeed shows that debt aversion - i.e. stating that borrowing for consumption is a bad idea is markedly lower for biased subjects (12.28\%) compared to unbiased ones $(36.36 \%)$.

In order to assess the predictive capacity of the leverage bias on general attitudes towards debt for consumption, we run a Bayesian multinomial logistic regression. Once again, we assume 
Table 8

Effect of the leverage bias on borrowing attitudes

\begin{tabular}{cccc}
\hline \hline & Averse & Seeker & Neutral \\
\hline Marginal effect & -.1783 & .2419 & -.0851 \\
$68 \%$ HPDI & {$[-.2381-.1119]$} & {$[.1970 .2991]$} & {$[-.1932-.0350]$} \\
Controls & Yes & Yes & Yes \\
Sample size & 68 & 68 & 68 \\
\hline \hline
\end{tabular}

Marginal effects from a Bayesian logistic regression of the measure of attitudes towards debt on a dummy equal to 1 if the subject is biased. The regression includes age, gender dummy, family size and family education level as covariates.

Prior $N(0,1)$ on all model coefficients. Random-walk Metropolis-Hastings sampling with 100000 MCMC sample size.

Values in parentheses are $68 \%$ highest posterior density intervals.

that the leverage bias has no predictive power over attitudes towards debt by setting a neutral $N(0,1)$ prior on the coefficient of the bias dummy. We find a strong deviation from our prior: the marginal effects reported in Table 8 indicate that being biased reduces the probability of being debt averse by roughly 18 percentage points, while increasing by 24 percentage points the probability of being "debt seeker" - i.e. stating that spending by borrowing is a good idea. ${ }^{12}$ These results suggest that the leverage bias corresponds to a positive attitude towards credit-financed consumption and a lower aversion to debt.

Table 9

Reaction to a financial emergency

\begin{tabular}{cccccc}
\hline \hline & Borrow & Use savings & Postpone & Cut & Other \\
\hline Biased & $43.86 \%$ & $14.04 \%$ & $7.02 \%$ & $33.33 \%$ & $1.75 \%$ \\
Unbiased & $9.09 \%$ & $36.36 \%$ & $9.09 \%$ & $36.36 \%$ & $9.09 \%$ \\
\hline \hline
\end{tabular}

Borrow: "Borrow money"; Use savings: "Spend out of savings"; Postpone: "Postpone payments"; Cut: "Cut back"; Other: "Other".

Attitudes in a financial emergency. Table 9 shows that a large number of subjects with the leverage bias feel comfortable with the idea of using debt to cope with the necessity of paying overdue bills (43.86\%), while most of unbiased subjects choose to use their savings or to cut other expenses $(72.72 \%$ in total). We run a Bayesian multinomial logit in order to evaluate the change in the predicted probability of each outcome associated with the leverage bias. In particular, we regress the set of responses to the hypothetical financial emergency on a dummy equal to 1 if the subject is biased. As in the previous analysis, we impose a Normal prior with zero mean and variance equal to 1 on the coefficient of the dummy. Table 10 shows that the leverage bias is associated with a 26.52 percentage points increase in the probability of borrowing money in case of financial difficulties, while reducing the probability to rely on own savings by approximately 19 percentage points. The key findings from this question therefore points to the existence of a relation between the leverage bias and the tendency to rely on credit in case of financial difficulties.

Perceived wealth and borrowing for consumption. In order to investigate the relationship between the leverage bias, perceived wealth and the likelihood to take on debt for consumption

\footnotetext{
${ }^{12}$ All tables reported in this Section include age, gender, family size and family education as controls. Appendix $\mathrm{B}$ reports the tables of all regressions with no controls.
} 
Table 10

Effect of the leverage bias on reactions to financial emergency

\begin{tabular}{cccccc}
\hline \hline & Borrow & Use savings & Postpone & Cut & Other \\
\hline Marginal effect & .2652 & -.1945 & -.0169 & -.0399 & -.0190 \\
$68 \%$ HPDI & {$[.2257 .3177]$} & {$[-.2460-.1351]$} & {$[-.0525 .0326]$} & {$[-.1015 .0248]$} & {$[-.0256 .0010]$} \\
Controls & Yes & Yes & Yes & Yes & Yes \\
Sample size & 68 & 68 & 68 & 68 & 68 \\
\hline \hline
\end{tabular}

Marginal effects from a Bayesian logistic regression of reactions to a financial emergency on a dummy equal to 1 if the subject is biased. The regression includes age, gender dummy, family size and family education level as covariates.

Prior $N(0,1)$ on all model coefficients. Random-walk Metropolis-Hastings sampling with 100000 MCMC sample size.

Values in parentheses are $68 \%$ highest posterior density intervals.

in a hypothetical scenario, we combine data from the answers to both the positive and negative net worth case and we classify the agents in three groups: Group 1 includes all subjects who choose HRP, namely the profile with greater asset-debt ratio; Group 2 features all subjects who are neutral to the composition of the balance sheet, that is those who would borrow under any of the two profiles, and those that are averse to debt and would not borrow at all; Group 3 gathers subjects with any other combination of answers (e.g. those who would borrow under any profile in the positive net worth case but choose HRP in the negative net worth case).

Table 11 reports that an overwhelming majority (roughly 75\%) of subjects with the leverage bias belong to the first group. In other words, biased subjects favor borrowing under HRP, both when net worth is positive and when is negative. On the contrary, a large majority of unbiased subjects belong to the second group, thus pointing to a substantial neutrality of their debt behavior with respect to the composition of the balance sheet, for a given level of net worth. Also in this case, we run a Bayesian multinomial logistic regression in which we regress the group variable on the bias dummy, by imposing a Normal prior with zero mean and variance equal to 1. Table 12 shows that being biased increases the probability of belonging to the first group by 37 percentage points, while reducing that of being a member of group 2 by 34 percentage points. Therefore, the pattern of answers that we observe seems to confirm the interaction between the leverage bias and the likelihood to take on debt: biased subjects generally favor borrowing under HRP, that is when their perceived wealth is higher, while unbiased subjects either tend to avoid the use of credit or are generally indifferent to the composition of the balance sheet. In fact, it is important to note that among unbiased subjects in group 2, the ratio between those who indicate that they would not take the loan under any profile and those who say they would take the loan in any case, is 2 to 3 . That is, a substantial majority of unbiased subjects are averse to the idea of taking on debt to consume, consistent with the answers reported in the previous questions on attitudes towards debt.

Table 11

Likelihood to take on a loan for consumption

\begin{tabular}{cccc}
\hline \hline & Group 1 & Group 2 & Group 3 \\
\hline Biased & $75.44 \%$ & $14.04 \%$ & $10.53 \%$ \\
Unbiased & $9.09 \%$ & $72.73 \%$ & $18.18 \%$ \\
\hline \hline
\end{tabular}

Group 1: subjects choosing the profile with greater asset-debt ratio; Group 2: subjects choosing "I would take the loan under any profile" and "I would not take the loan under any profile"; Group 3: all other combinations.

Summing up our key findings on attitudes towards debt: 
Table 12

Effect of the leverage bias on the likelihood to take on debt

\begin{tabular}{cccc}
\hline \hline & Group 1 & Group 2 & Group 3 \\
\hline Marginal effect & .3711 & -.3432 & -.0640 \\
68\% HPDI & {$[.3251 .4240]$} & {$[-.3997-.2869]$} & {$[-.1049-.0098]$} \\
Controls & Yes & Yes & Yes \\
Sample size & 68 & 68 & 68 \\
\hline \hline
\end{tabular}

Marginal effects from a Bayesian logistic regression of group belonging on a dummy equal to 1 if the subject is biased. The regression includes age, gender dummy, family size and family education level as covariates.

Prior $N(0,1)$ on all model coefficients. Random-walk Metropolis-Hastings sampling with $100000 \mathrm{MCMC}$ sample size.

Values in parentheses are $68 \%$ highest posterior density intervals.

- Biased subjects are less debt averse than unbiased subjects, as they feel significantly more comfortable with the idea of borrowing to finance consumption.

- Results confirm the predictive power of the leverage bias on the likelihood to rely on credit as a means to deal with overdue payments. While we do not specify credit conditions, borrowing in a context of financial difficulty may often trigger a perverse spiral with increasing costs of debt (Bertrand and Morse, 2011; Mullainathan and Shafir, 2014; Shah et al., 2012)

- The leverage bias corresponds to a markedly larger tendency to borrow under profiles that have greater asset-debt ratio. This confirms that, for a given net worth, biased subjects feel wealthier for higher values of the asset-debt ratio and this entails a greater likelihood to take on debt for consumption. On the contrary, unbiased subjects correctly perceive the two profiles as fungible, thus making choices that are independent of the balance sheet composition. Moreover, consistent with the results from the first question, unbiased subjects generally oppose the idea of credit-financed spending.

\subsubsection{Consumption}

We start by investigating the relationship between the leverage bias and attitudes towards savings and time preferences. We do so by asking participants whether they self identify as "the type of person that prefers to spend money and enjoy it today or save more for the future", with a binary choice: "spend now" and "save for the future". Parker (2017) uses this question in a survey as a proxy of the patience/impatience of the subjects. He shows that answers to this question strongly predict consumption behavior, in that people who report being "spenders" do not smooth consumption and have a significantly larger spending response to predictable lump-sum payments, compared to people who self-identify as "savers".

We test whether the leverage bias predicts the likelihood to increase spending out of unexpected gains. To do this, we modify the question introduced by Fuster et al. (2018) to describe an hypothetical scenario in which subjects unexpectedly receive a one-time payment and they are asked to indicate what they would do in the following month. Agents can choose among three options: i) they can increase spending more than if they had not received the payment; ii) they can decrease spending; or iii) they can keep it unchanged. Compared to Fuster et al. (2018), we repeat the question only twice: first, with a $€ 500$ payment; then, with $€ 5000$. However, in order to test the relationship between perceived wealth and the likelihood to increase spending, we also introduce a third question with a $€ 500$ payment, in which each subject is shown two financial profiles with identical net worth but different balance sheet composition. Subjects are eventually asked to state under which of the two profiles they would be more likely to increase 
their expenses in the following month. They have the possibility to state that they would increase their expenses in either, or neither, case. If greater perceived wealth were linked to a higher likelihood to increase spending out of unexpected gains, biased subjects should choose HRP, while unbiased subjects should make a decision that does not depend on the composition of the balance sheet, given the value of the net worth.

In all three questions, subjects who would increase their expenses are eventually asked the exact amount. This allows us to estimate marginal propensities to consume out of unexpected gains, similar to Fuster et al. (2018).

Table 13

Saving type (patience)

\begin{tabular}{ccc}
\hline \hline & Patient & Impatient \\
\hline Biased & $31.58 \%$ & $68.42 \%$ \\
Unbiased & $81.82 \%$ & $18.18 \%$ \\
\hline \hline
\end{tabular}

Patient: "Save for the future"; Impatient: "Spend now".

Table 14

Effect of the leverage bias on impatience

\begin{tabular}{cc}
\hline \hline Marginal effect & .3901 \\
$68 \%$ HPDI & {$[.3455 .4462]$} \\
Controls & Yes \\
Sample size & 68 \\
\hline
\end{tabular}

Marginal effects from a Bayesian logistic regression of the measure of attitudes towards debt on a dummy equal to 1 if the subject is biased. Controls include age, gender dummy, family size and family education level as covariates.

Prior $N(0,1)$ on all model coefficients. Random-walk Metropolis-Hastings sampling with 100000 MCMC sample size.

Values in parentheses are $68 \%$ highest posterior density intervals.

Findings on patience and saving type. Table 13 shows a major difference between the share of patient and impatient subjects within each of the two groups. In fact, a large majority of biased subjects report being the type of person that is more prone to spend and enjoy the present $(68.42 \%)$, while the majority of unbiased subjects self-identify as savers $(81.82 \%)$. In Table 14 we report the marginal effects from a Bayesian logit model in which we regress a dummy for patience on the bias dummy. We impose a neutral $N(0,1)$ prior on the coefficient of the dummy. We find a significant departure from the prior. Indeed, results confirm the strong predictive power of the leverage bias over the measure of impatience, in that being biased is associated with an increase in the probability of being the type of person that spends now and enjoys the present.

Spending out of unexpected gains. Table 15 suggests that biased subjects are generally more prone to increase spending out of an unexpected gain of $€ 500$ compared to subjects with no leverage bias (54.39\% vs. $18.18 \%$ ). However, when we increase the amount of the windfall from $€ 500$ to $€ 5000$, the share of subjects who would increase their consumption rises in both groups $(63.16 \%$ for biased agents and $45.54 \%$ for unbiased ones). This result is in line with the findings by Fuster (2018), who finds a size effect which leads respondents to be more willing to increase spending when the size of the windfall increases.

We also find that the rise in the share of subjects who would increase their spending is larger among unbiased subjects (about 27 percentage points against an increase of about 9 percentage 
Table 15

Spending out of unexpected gains

\begin{tabular}{ccccccc}
\hline \hline Gain & & Biased & & \multicolumn{3}{c}{ Unbiased } \\
& Less & Same & More & Less & Same & More \\
\hline$€ 500$ & $3.51 \%$ & $42.11 \%$ & $54.39 \%$ & $9.09 \%$ & $72.73 \%$ & $18.18 \%$ \\
$€ 5000$ & $1.75 \%$ & $35.09 \%$ & $63.16 \%$ & $9.09 \%$ & $45.54 \%$ & $45.54 \%$ \\
\hline \hline
\end{tabular}

Less: "I would spend less than if I had not received the $€ 500$ "; Same: "I would spend the same as if I had not received the €500"; Less: "I would spend more than if I had not received the € 500". Repeated also for €5000.

points for biased subjects), thus narrowing the gap between the two groups (from about 36 percentage points to about 18 percentage points).

Table 16

Effect of the leverage bias on spending response

\begin{tabular}{cccc}
\hline \hline & Less & Same & More \\
\hline Marginal effect, $€ 500$ scenario & .0028 & -.2144 & .2184 \\
$68 \%$ HPDI & {$[-.0122 .0241]$} & {$[-.2756-.1633]$} & {$[.1706 .2757]$} \\
& & & \\
Marginal effect, $€ 5000$ scenario & -.0195 & -.1021 & .1165 \\
$68 \%$ HPDI & {$[-.0261 .0029]$} & {$[-.1604-.0440]$} & {$[.0599 .1708]$} \\
Controls & & & \\
Sample size & Yes & Yes & Yes \\
\hline \hline
\end{tabular}

Marginal effects from a Bayesian logistic regression of spending responses on a dummy equal to 1 if the subject is biased. The regression includes age, gender dummy, family size and family education level as covariates.

Prior $N(0,1)$ on all model coefficients. Random-walk Metropolis-Hastings sampling with 100000 MCMC sample size.

Values in parentheses are $68 \%$ highest posterior density intervals.

Table 16 reports the marginal effects from the Bayesian logit model in which we regress the type of spending response on the bias dummy, both in $€ 500$ and the $€ 5000$ case. As in all other regressions we impose a neutral $N(0,1)$ prior. The results clearly show that subjects with the leverage bias have a larger probability of increasing their expenses when receiving unexpected income in both scenarios (21.84 and 11.65 percentage points respectively). Moreover, the point estimates of the average marginal propensity to consume (MPC), conditional on spending more, are equal to 0.38 and 0.32 for biased and unbiased subjects respectively, in the $€ 500$ scenario, and 0.23 and 0.20 , in the $€ 5000$ scenario. Also in this case we find a size effect, such that an increase in the amount of the windfall decreases the average MPC of both groups. Nonetheless, biased subjects seem to have a more pronounced reaction to unexpected positive income shocks in both scenarios, thus suggesting lower consumption smoothing compared to unbiased subjects.

We finally analyze the results from our very last question, in which we replicate the $€ 500$ scenario with the introduction of two profiles with equal (positive) net worth but different values of assets and liabilities. Table 17 shows that biased subjects are much more likely to increase their expenses under the profile with higher asset-debt ratio (71.93\%), while unbiased subjects seem neutral to the amount of assets and liabilities (81.82\%). In particular, within unbiased subjects in the group classified as neutral we find that $44.44 \%$ state that they would increase their expenses in any case, while $55.56 \%$ would not do so, regardless of the composition of the balance sheet. Results from the Bayesian logistic regression reported in Table 18 indicate that 
Table 17

Spending out of unexpected gains for profile type

\begin{tabular}{cccc}
\hline \hline & $H R P$ & $L R P$ & Neutral \\
\hline Biased & $71.93 \%$ & $8.77 \%$ & $19.30 \%$ \\
Unbiased & $9.09 \%$ & $9.09 \%$ & $81.82 \%$ \\
\hline \hline
\end{tabular}

Percentage of subjects that would increase spending out of an unexpected gain under the high-ratio profile (HRP), low-ratio profile (LRP) and under any profile (or would not increase spending at all).

Table 18

Effect of the leverage bias on increase in consumption

\begin{tabular}{cccc}
\hline \hline & $H R P$ & $L R P$ & Neutral \\
\hline Marginal effect & .3951 & -.0458 & -.3570 \\
$68 \%$ HPDI & {$[.3465 .4550]$} & {$[-.0723-.0040]$} & {$[-.4113-.3134]$} \\
Controls & Yes & Yes & Yes \\
Sample size & 68 & 68 & 68 \\
\hline \hline
\end{tabular}

Marginal effects from a Bayesian logistic regression of profile selection on a dummy equal to 1 if the subject is biased. The regression includes age, gender dummy, family size and family education level as covariates.

Prior $N(0,1)$ on all model coefficients. Random-walk Metropolis-Hastings sampling with $100000 \mathrm{MCMC}$ sample size.

Values in parentheses are $68 \%$ highest posterior density intervals.

being biased increases the likelihood to rise consumption under HRP by 39.51 percentage points, while reducing by 4.58 percentage points the probability of increasing consumption regardless of the balance sheet composition.

Summing up:

- The leverage bias corresponds to a considerably larger probability of being a more impatient type of person, self-identifying as a spender, rather than a saver. This is also identified in a larger probability of increasing consumption out of positive gains.

- Similar to our question on credit-financed spending, a higher asset-debt ratio implies a greater value of perceived wealth, which leads to a higher likelihood to increase spending for subjects with the leverage bias. The majority of unbiased subjects, instead, do not increase consumption or state that they would increase it regardless of the balance sheet composition.

In general, our laboratory experiment highlights the existence a deviation from standard consumer theory and the predominance of a bias that, based on balance sheet composition, leads the majority of subjects to have different perceptions associated with financially equivalent balance sheet profiles.

The key characteristics that seems to differentiate biased subjects from the rest is the lower level of cognitive reflection. The leverage bias is related to a type of thinking that is fast, intuitive and makes limited use of attention.

Finally, the leverage bias predicts low debt aversion and a greater tendency to rely on credit as a means to finance consumption and react to a financial emergency. The bias also correlates with a positive spending reaction to unexpected gains, thus predicting lower consumption smoothing compared to unbiased individuals. 


\section{A model of behavioral inattention}

In this section we introduce a simple two-period optimal consumption model to explain our results. The model features two types of agents: (i) a standard rational agent, representing unbiased subjects in our experiment, who will be the benchmark of the model; (ii) a behavioral agent à la Gabaix $(2014,2019)$, who has a wrong perception of her wealth due to low cognitive sophistication and inattention. In particular, our behaviorally inattentive agent has the following distinctive characteristics:

- In line with the sparse-max operator, described in Gabaix (2014, 2019), the optimization problem for this agent consists of two steps. In the first step, the agent builds a perceived value of her total net wealth by choosing the optimal amount of attention to allocate to the problem; then, she chooses the optimal consumption level, conditional on her perception of wealth. Consumption allocation is therefore the outcome of a process endowed with procedural rationality but no substantive rationality (Simon, 1978), as the agent's consumption decision is not determined exclusively by the characteristics of the environment but, rather, by her perception of it.

- The agent's System 1 generates a noisy representation of her wealth, whose level is positively correlated to the magnitude of the asset-debt ratio - in line with the leverage bias found in the experiment. However, the level of cognitive sophistication of the agent - that is, a product of the interaction between System 1 and System 2 (Kahneman, 2003a,b, 2011; Stanovich and West, 2003) - determines the optimal amount of attention allocated to the true value of wealth, thereby establishing whether perceived wealth is ultimately closer to the true level or to the noisy representation of it.

- In line with our experimental results, the biased agent is characterized by a predominance of System 1 over System 2, due to a low level of cognitive sophistication. Hence, she does not allocate full attention to the true value of her wealth. This results in a perceived level of wealth that is different from the actual value.

\subsection{Rational (unbiased) agent}

Let us start by describing the behavior of the rational agent. We assume a well-behaved utility function, such that the rational agent chooses the intertemporal consumption allocation optimally by maximizing her utility subject to the budget constraint in period one and in period two. Hence, she solves the following problem:

$$
\max U\left(c_{1}, c_{2}\right)=U\left(c_{1}\right)+\beta U\left(c_{2}\right)
$$

s.t.

$$
\left\{\begin{array}{l}
c_{1}=y_{1}+b \\
c_{2}+(1+r) b=y_{2}
\end{array}\right.
$$

where $c_{t}(t=1,2)$ identifies consumption in each period, while $y_{t}(t=1,2)$ represents the endowment in each period. In particular, $y_{1}$ is assumed to be determined by two components: the actual income received in period $1\left(\hat{y}_{1}\right)$ and a stock of net wealth $(N W)$ composed of assets $(A)$ and debt $(D)$, so that $y_{1}=\hat{y_{1}}+N W$, where $N W=A-D$. Finally, $r$ is the real interest rate and $b$ is either savings, if positive, or debt, if negative. Hence, the agent total (net) wealth is $w=y_{1}+\frac{y_{2}}{1+r}$, while the intertemporal budget constraint is 


$$
c_{2}=(1+r)\left(y_{1}-c_{1}\right)+y_{2}
$$

The optimization problem yields the standard Euler Equation:

$$
\frac{U_{c_{1}}^{\prime}}{U_{c_{2}}^{\prime}}=\beta(1+r)
$$

By combining Equations 4 and 5, we find the optimal consumption levels for the rational agent, which will be a function of the interest rate and the total net wealth of the agent. In the following we will refer to optimal consumption allocation for the rational agent in period one and period two with $c_{1}^{*}\left(r, y_{1}, y_{2}\right)$ and $c_{2}^{*}\left(r, y_{1}, y_{2}\right)$ respectively.

\subsection{Biased agent}

We model the behavior of the biased agent after the behavioral inattention setup introduced by Gabaix (2014) with some slight departures. As in Gabaix, the agent faces the standard optimization problem, but she solves it in two steps according to the sparse-max operator (Gabaix, 2014, 2019): first, she decides the optimal amount of attention to allocate to the problem, so as to form a perceived value of wealth; second, the agent chooses the optimal consumption allocation of the two periods, conditional on her perception. ${ }^{13}$

In line with the experimental results, the biased agent in our model is characterized by the leverage bias and limited cognitive sophistication and attention. Hence, the agent does not pay full attention to the problem, so that her perceived wealth does not correspond to the actual wealth. As a consequence, her consumption allocation will differ from that of the rational agent. In the following we provide the details.

\subsubsection{Behavioral inattention}

The biased agent's actual net wealth is the same as the rational agent, that is $w=y_{1}+y_{2} /(1+r)$. We assume that her perceived wealth is $w^{s}=y_{1}^{s}+y_{2} /\left(1+r^{s}\right)$, where the ${ }^{s}$ superscript represents perceived (or sparse) values. Hence, the agent's perceived wealth deviates from her actual wealth due to a sparse representation of the endowment of period 1 and the interest rate. ${ }^{14}$

Assumption 1: $y_{1}^{s}$ and $r^{s}$ are defined as the following convex combinations:

$$
\begin{aligned}
& y_{1}^{s}=m_{1} y_{1}+\left(1-m_{1}\right) y_{1}^{d} \\
& r^{s}=m_{2} r+\left(1-m_{2}\right) r^{d}
\end{aligned}
$$

where variables with the ${ }^{d}$ superscript are individual default values, which identify the guess that spontaneously comes to mind with no time to think (Gabaix, 2014), or under limited cognitive resources. In Bayesian terms, the default could also be interpreted as the prior generated by System 1, which, being fast and inattentive, produces an inaccurate guess. The variable $m_{i} \in[0,1], \forall i=1,2$, is a measure of attention, such that $m_{i}=1$ implies full attention, while $m_{i}=0$ implies no attention. Any value $0<m_{i}<1$ implies an inaccurate perception of the true value of the corresponding variable. When $m_{i}$ increases, the agent relies less on the default and more on the true value, as System 2 takes over System 1.

\footnotetext{
${ }^{13}$ We model behavioral inattention via sparse-maxity, rather than following the approach with an entropy penalty by Sims (2003), because "the sparse max allows for source-dependent inattention, and is more tractable" (Gabaix, 2014, p. 1696). In fact, Sims (2003) formulation dampens equally all dimensions, while in the sparsemax approach developed by Gabaix (2014), the level of attention is dimension specific, so that less important dimensions are dampened more.

${ }^{14}$ Notice that one could obtain similar qualitative results by applying sparsity on $y_{2}$ or other combinations of the components of wealth. However, this choice leads to an analytically simpler solution without altering the conclusions.
} 
Assumption 2: As a microfoundation, we model the default values as the true values altered by a distortion factor:

$$
\begin{aligned}
y_{1}^{d} & =y_{1}+g_{y_{1}} \\
r^{d} & =r-g_{r}
\end{aligned}
$$

where $g_{y_{1}}$ and $g_{r}$ represent the distortion in the priors generated by System 1. Specifically, we describe $g_{y_{1}}=\psi A / D$, with $\log \psi \sim N(0, \eta)$, where $\eta$ is a finite variance, and $g_{r}=\gamma A / D$, with $\gamma \sim U(0,1) .{ }^{15}$ Equations 8 and 9 imply $y_{1}^{d}>y_{1}$ and $r^{d}<r$, which entail $w^{s}>w$, for any $m_{i}<1, \forall i=1,2$. In other words, we assume that (i) the inaccurate guess on the value of the endowment generated by System 1 exceeds its true value and (ii) the magnitude of the deviation of $y_{1}^{d}\left(r^{d}\right)$ from $y_{1}(r)$ depends on a distortion affected by the asset-debt ratio. ${ }^{16}$ This aligns the idea that the intensity of the distortion should be directly connected to the size and nature of the noise in perceptual judgments (Khaw et al., 2019), while also capturing the essence of a key experimental finding, namely the leverage bias: a greater asset-debt ratio impacts positively on the mental representation of wealth, thereby increasing its deviation from the given level of actual wealth.

Lemma 1: Under Assumption 1 and Assumption 2 we have:

$$
\begin{aligned}
& y_{1}^{s}=y_{1}+\left(1-m_{1}\right) g_{y_{1}}>y_{1} \\
& r^{s}=r-\left(1-m_{2}\right) g_{r}<r
\end{aligned}
$$

Hence, the overall biased perception of wealth is determined by two factors:

- The noisy representation of the true values generated by System 1, which, in turn, depends on the magnitude of the asset-debt ratio. In line with the leverage bias found in the experiment, a greater asset-debt ratio increases the value of the fast and inaccurate guesses produced by the less sophisticated mental process of System 1.

- The optimal level of attention $m_{i}^{*}$, which may be interpreted as the outcome of the interaction between System 1 and System 2, as in dual process theory (Kahneman, 2003a,b). For a sophisticated agent, System 2 fully overtakes System 1 so that $m_{i}=1, \forall i=1,2$. The agent is therefore rational and fully attentive, thereby having an unbiased perception that corresponds to the true value of wealth. On the contrary, System 1 prevails and $m_{i}$ tends to zero for an agent with poor cognitive sophistication. This agent is rational but inattentive, thus having a perceived value of wealth that relies on her default and diverges from the true level. The overall amount of the deviation therefore ranges between $\left[0, g_{y_{1}}\right]$ for $y_{1}$ and $\left[0, g_{r}\right]$ for $r$.

Following Gabaix (2014, 2019), we define the optimal level of attention $\left(m^{*}\right)$ as given by a function with two additive components: the utility loss from imperfect attention and the psychological cost for the lack of sparsity. ${ }^{17}$ Specifically:

\footnotetext{
${ }^{15}$ Khaw et al. $(2017,2019)$ propose that judgments and choices be based on noisy mental representation of the situation and this involves an average bias in the optimal rule for forming such judgments and making these choices. In fact, "if there were no random noise in the internal representations on which the judgments are based, there should (if the subject forms optimal Bayesian judgments) be no noise in perceptual judgments, and no bias either" (Khaw et al., 2019, p.4). This is philosophically analogous to our set up, in which there exists a strong link between the default values - i.e. the noisy sensory data generated by System 1 - and the perceptual representation of wealth.

${ }^{16}$ In the paper we focus on the case in which $w^{s}>w$, as this produces results that align our experimental findings (as shown later in the text). Appendix D describes the case in which $y_{1}^{d}<y_{1}$ and $r^{d}>r$, so that $w^{s}<w$.

${ }^{17}$ The interested reader is left to refer to Gabaix (2014) for a detailed explanation for this particular functional form.
} 


$$
m^{*}=\underset{m \in[0,1]}{\arg \min } \frac{1}{2} \sum_{i=1}^{2}\left(1-m_{i}\right)^{2} \Delta_{i i}+k(\theta) \sum_{i=1}^{2} m_{i}^{\alpha}
$$

where, in our setting, $\Delta_{i i}:=-\sigma_{i}^{2} a_{x_{i}} U_{a a} a_{x_{i}}$ is the benefit that the consumer enjoys when her attention on dimension $i$ goes from zero to one. $U_{a a}$ is the second derivative of the utility function with respect to action $a$, while $a_{x i}:=\frac{\partial a}{\partial x_{i}}$ identifies the marginal effect of a change in variable $x_{i}$ on the action (that is $-U_{a a}^{-1} U_{a x_{i}}$ ), evaluated at the default values of the action and the variable $x_{i}{ }^{18}$ In our set-up $x_{i}=\left[y_{1}, r\right]$ and $a=c_{1}$. When unable to observe the variable $x_{i}$, the agent uses the expected magnitude as a proxy, thus setting $\sigma_{i}=\mathbf{E}\left[x_{i}^{2}\right]^{1 / 2}$ and, trivially, $\Delta_{i i}:=-\mathbf{E}\left[x_{i}^{2}\right] a_{x_{i}} U_{a a} a_{x_{i}}$. Finally, the function $k(\theta)$ is the penalty for the lack of sparsity, such that the term $k(\theta) m_{i}^{\alpha}$ represents the psychological cost of attention. We follow Gabaix (2014) and assume that $\alpha=1$, so as to have both sparsity and continuity in the attention function. However, since attention is cognitively costly (Kahneman, 1973) and entails the allocation of scarce cognitive resources (Gabaix, 2019), we depart from the setup introduced in Gabaix (2014) by assuming that $k$ depends on the level of cognitive sophistication of the agent $(\theta)$. In particular:

$$
k(\theta)= \begin{cases}0, & \forall \theta \geq \bar{\theta} \\ \in\left(0, k_{\text {max }}\right], k(\theta)^{\prime}<0 & \forall \theta<\bar{\theta}\end{cases}
$$

where $\bar{\theta}$ represents a threshold in the level of cognitive sophistication, such that $\theta \geq \bar{\theta}$ corresponds to the rational agent, who is endowed with a level of cognitive reflection that corresponds to full attention and a correct perception of the true value of wealth. Nonetheless, biased subjects in our experiment have a greater tendency to rely on System 1, thus employing limited cognitive resources and attention. Hence, the case $\theta<\bar{\theta}$ corresponds to the biased agent, who has a low level of cognitive sophistication that entails a high cost of attention, low $m^{*}$ and a level of perceived wealth that exceeds the actual value. ${ }^{19}$ We assume that for zero cognitive sophistication, $k(0)=k_{\max }$ in order to avoid an infinitely positive cost of attention for an extremely cognitively unsophisticated agent.

From Equation 12 we obtain the optimal level of attention on dimension $i$ as a function of the cognitive cost $k(\theta)$ and the benefit $\Delta_{i i}$ :

$$
m_{i}^{*}=\max \left(1-\frac{k(\theta)}{\Delta_{i i}}, 0\right)
$$

where, in our setting, $\Delta_{11}:=-\mathbf{E}\left[y_{1}^{2}\right] a_{y_{1}} U_{c_{1} c_{1}} a_{y_{1}}$ and $\Delta_{22}:=-\mathbf{E}\left[r^{2}\right] a_{r} U_{c_{1} c_{1}} a_{r}$.

Therefore, for a given level of $\theta<\bar{\theta}$, if the associated cost is greater or equal to the benefit, i.e. $k(\theta) \geq \Delta_{i i}$, attention on dimension $i$ will be zero. In all cases in which $k(\theta)<\Delta_{i i}$, the agent will always pay at least some attention to the variable $i$. When $k(\theta)=0$ (i.e. when $\theta \geq \bar{\theta}$ ), attention is maximum and equal to 1 , regardless of $\Delta_{i i}$, and the agent is unbiased. ${ }^{20}$

Figure 4.a plots the cognitive cost and optimal attention on $i$ as a function of the level of cognitive sophistication, for a given value of $\Delta_{i i}$. For $\theta \geq \bar{\theta}$, the cost $k(\theta)$ is zero, optimal attention is $m_{i}^{*}=1$ and the agent is unbiased. When $\theta<\bar{\theta}$, the lower the level of cognitive sophistication, the higher the corresponding cost and the lower the optimal level of attention.

\footnotetext{
${ }^{18}$ The default action corresponds to the optimal action under default values of $x$.

${ }^{19}$ The specific functional form of $k(\theta)$ in the interval $\left(0, k_{m a x}\right]$ for $\theta<\bar{\theta}$ is not relevant for the purpose of our analysis. For the sake of simplicity we assume it is a linear function.

${ }^{20}$ We assume that $\max \left(\Delta_{i i}\right) \leq k_{\max }$, so that the benefit of attention cannot exceed the maximum cost. This rules out the possibility that an agent with zero cognitive sophistication (and, therefore, maximum cost) has positive attention to the variable $i$.
} 
When $\theta$ is such that $k(\theta)$ exceeds $\Delta_{i i}$, optimal attention is zero. Figure 4.b shows optimal attention on $i$ as a function of $\Delta_{i i}$, for a given level of cognitive sophistication. When $\Delta_{i i} \leq k(\theta)$ optimal attention is zero, otherwise $m_{i}^{*}$ increases as the benefit exceeds the cost of attention.

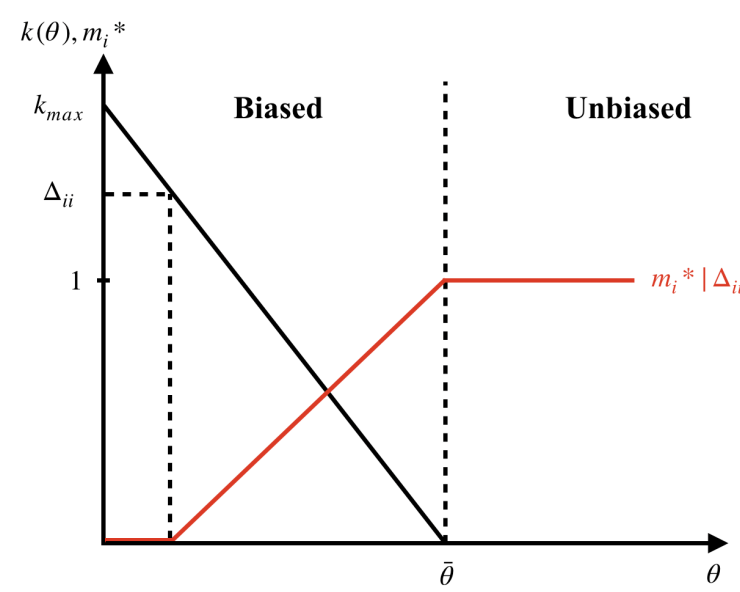

(a)

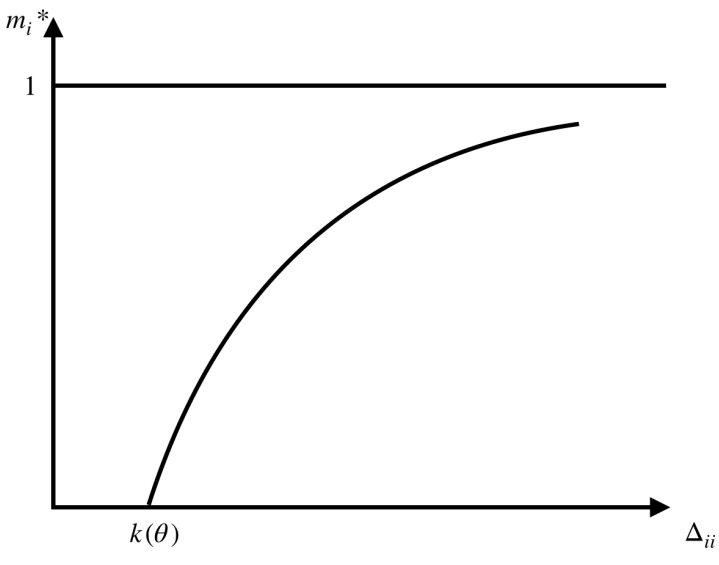

(b)

Figure 4: (a): attention cost $\left(k(\theta)\right.$, in black) and optimal attention $\left(m_{i}^{*}\right.$, in red) as a function of the level of cognitive sophistication $(\theta)$, for a given value of $\Delta_{i i}$. (b): optimal attention as a function of $\Delta_{i i}$, for a given value of $\theta$.

Summing up, our set up incorporates the main features of the standard sparse-max operator introduced in the behavioral inattention model by Gabaix $(2014,2019)$. In fact, attention on each variable increases (1) when the magnitude of the variable is higher; (2) when the variable impacts more on the action $a$; (3) if an imperfect action leads to a greater cost. However, differently from the original set-up, the cognitive cost $k$ is a function of the level of cognitive sophistication of the agent and default values depend on the level of the asset-debt ratio. This allows to capture the following:

1. The level of cognitive sophistication correlates with the misperception of wealth. In the experiment, subjects with low CRT scores are more likely to be biased. In the model, when System 1 prevails over System 2, the agent is sparse and her level of cognitive sophistication is $\theta<\bar{\theta}$. Therefore, her attention is lower and she relies more on the inaccurate prior generated by System 1 (i.e. the default values of the variables).

2. Perceived wealth increases for higher values of the asset-debt ratio. The value of the fast and inaccurate prior of System 1 depends positively on the level of the asset-debt ratio. Therefore, for a given level of cognitive sophistication and attention, a higher asset-debt ratio impacts positively on the perceived wealth of the biased agent.

\subsubsection{Optimal action}

After choosing attention optimally, the agent chooses the allocation of consumption conditional on her sparse representation of wealth. Hence, she solves the following problem:

$$
\max U\left(c_{1}, c_{2}\right)=U\left(c_{1}\right)+\beta U\left(c_{2}\right)
$$

s.t.

$$
c_{2}=\left(1+r^{s}\right)\left(y_{1}^{s}-c_{1}\right)+y_{2}
$$


The Euler equation for the sparse agent therefore is:

$$
\frac{U_{c_{1}}^{\prime}}{U_{c_{2}}^{\prime}}=\beta\left(1+r^{s}\right)
$$

From the problem above we find the optimal allocation of consumption conditional on the biased perception of wealth, $c_{1}^{s}\left(r^{s}, y_{1}^{s}, y_{2}\right)$ and $c_{2}^{s}\left(r^{s}, y_{1}^{s}, y_{2}\right)$. However, this allocation lies on the perceived budget constraint, which is different from the actual one. Therefore, the optimal allocation is not feasible.

As pointed out by Gabaix (2014), the sparse agent is behavioral but smart enough to exhaust the true budget constraint, thereby adjusting the allocation of consumption accordingly. Since the agent is biased, the adjusted allocation $\left(c_{1}^{a}, c_{2}^{a}\right)$ has to depend on the perceived value of wealth (i.e. $r^{s}$ and $y_{1}^{s}$ ) while also being feasible, so that $c_{1}^{a}+\frac{c_{2}^{a}}{1+r}=y_{1}+\frac{y_{2}}{1+r}$. Therefore, we define an as-if intertemporal budget constraint as follows:

$$
c_{2}^{a}=\left(1+r^{s}\right)\left(y_{1}^{s}-c_{1}^{a}\right)+y_{2}^{\prime}
$$

Following Gabaix, the adjustment occurs by finding the value of $y_{2}^{\prime}$ that guarantees that the adjusted allocation is feasible, i.e. it is along the true budget constraint. Hence, the following condition has to be satisfied:

$$
c_{1}^{a}\left(r^{s}, y_{1}^{s}, y_{2}^{\prime}\right)+\frac{c_{2}^{a}\left(r^{s}, y_{1}^{s}, y_{2}^{\prime}\right)}{1+r}=y_{1}+\frac{y_{2}}{1+r} .
$$

Therefore, the biased agent solves the following problem:

$$
\text { find } y_{2}^{\prime} \quad \text { s.t. } \quad C^{a}\left(r^{s}, y_{1}^{s}, y_{2}^{\prime}\right)=w
$$

where $C^{a}\left(r^{s}, y_{1}^{s}, y_{2}^{\prime}\right)$ represents total adjusted consumption, that is the optimal allocation that is also feasible.

\subsection{Rational vs. adjusted (sparse) allocation}

We now identify the conditions under which the model replicates our experimental results. We know that biased subjects are more likely to borrow for consumption, relative to unbiased subjects. We also know that the leverage bias is associated with a larger probability of being a spender, rather than a saver, and a greater tendency to increase spending out of unexpected gains.

Proposition 1: A necessary condition for the biased agent to be a borrower in period 1 i.e. $c_{1}^{a}>y_{1}-$ and have positive consumption in period $2-i . e . c_{2}^{a}>0-i s$

$$
y_{2} \frac{1+r^{s}}{1+r}-\left(y_{1}^{s}-y_{1}\right)\left(1+r^{s}\right)<y_{2}^{\prime}<y_{2}-\left(y_{1}^{s}-y_{1}\right)\left(1+r^{s}\right)
$$

Hence, for any value of $y_{2}^{\prime}$ that meets condition 20, in the first period the biased agent consumes more than the period 1 endowment, thereby being a borrower. Condition 20 also allows for non-negative consumption in the second period (see Appendix $\mathrm{C}$ for the proof). 
We now identify the condition under which the adjusted consumption of the biased agent in period 1 is larger than the consumption of the rational agent in the same period. To this purpose, we assume a Constant Relative Risk Aversion (CRRA) utility function. ${ }^{21}$

Proposition 2: Under the assumption of constant relative risk aversion, and Lemma 1, $\forall$ $y_{2}^{\prime}$ satisfying $18, c_{1}^{a}>c_{1}^{*}$.

The adjusted consumption of the biased agent in period 1 is always larger than the consumption of the rational agent in the same period.

Hence, as long as the biased agent perceives her wealth as larger than its true value, after adjusting the allocation of consumption according to the as-if budget constraint, the biased agent always wants to consume more than the rational agent in the first period (Appendix $\mathrm{C}$ contains a detailed proof). Proposition 2 also implies that, if both agents are borrowers in $t=1$, the biased agent borrows more than the rational agent. This is in line with the experimental findings suggesting that biased subjects are more likely to identify as spenders rather than savers and have a lower aversion to debt, compared to unbiased subjects.

Proposition 3: Under the assumption of constant relative risk aversion, and Lemma 1 we have:

$$
\frac{\partial c_{1}^{a}}{\partial y_{1}}>\frac{\partial c_{1}^{*}}{\partial y_{1}}
$$

Period-1 consumption of the biased agent has a positive and more pronounced response to unexpected changes in $y_{1}$ compared to the consumption of the rational agent in the same period.

This result replicates our experimental finding, as biased subjects report a greater average propensity to consume out of unexpected positive gains compared to unbiased subjects.

Finally, not only the model matches our experimental findings, but it also aligns existing evidence showing that, on average, household consumption responds significantly to unanticipated income shocks (Agarwal and Qian, 2014; Johnson et al., 2006). The size of the response is markedly higher compared to the estimates of standard economic models (Beshears et al., 2018), which typically predict excess consumption smoothing that is in contrast with the data (Gorbachev, 2011; Jappelli and Pistaferri, 2010). On the contrary, our model produces a pattern of consumption that, in the case of the biased agent, is characterized by greater volatility and lower consumption smoothing, with respect to the standard neoclassical benchmark.

\subsection{Quantitative analysis}

In this section we carry out two estimation exercises. First, we exploit the model and experimental data in order to estimate the relationship between cognitive sophistication and the balance sheet composition. In the second exercise, we also estimate the combinations of optimal attention and System 1 priors that yield the observed ratio between the marginal propensities to consume of the two types of subjects in the experiment.

The model implies that lower cognitive abilities result in a greater cost of attention (Equation 13) and, ceteris paribus, lower optimal attention on the variables of the problem (Equation 14). This leads the biased agent to rely more on the default values generated by System 1 and less on the true values (Equations 6 and 7). A biased subject with low cognitive sophistication should therefore be more sensitive to the level of the asset-debt ratio. As such, we should expect a negative correlation between cognitive abilities and the sensitivity to the asset-debt ratio.

By using experimental data we test this relationship. In fact, the dispersion in the grades assigned by subjects to the profiles shown in PGT may be used as a proxy of the sensitivity of

\footnotetext{
${ }^{21}$ It is indeed necessary to assume a functional form for the utility function in order to compare the behavior of the two agents. See Appendix C for a detailed discussion on this.
} 
their perceptions to the asset-debt ratio, while individual CRT scores represent a measure of cognitive sophistication. Since unbiased subjects assign the same grade to all profiles, regardless of the balance sheet composition (for a given net worth), their optimal attention on all variables of the problem is equal to 1 and their sensitivity to the asset-debt ratio is zero for any level of cognitive sophistication $\theta$. This indeed implies no deviation of the perceived value of wealth from the true one. Instead, within the group of biased subjects we should observe a negative correlation between CRT scores and the variance of individual grades. Indeed, less cognitively sophisticated biased subjects - i.e. those with lower values of $\theta$ - pay lower attention to the true values and, therefore, should be more sensitive to the differences in the asset-debt ratios of the profiles.

We perform a regression of the variance of individual grades on CRT scores, by imposing the prior of neutrality $N(0,1)$ on the coefficient. Our result in Table 19 indicates that an increase in the CRT score reduces the dispersion of the grades assigned by biased subjects by roughly 9 percentage points. This result confirms that the level of cognitive sophistication of biased subjects is inversely related to the sensitivity of individual perceptions to the asset-debt ratio in PGT. In other words, a biased subject with lower cognitive sophistication is more inattentive and, therefore, more sensitive to the composition of the balance sheet.

\section{Table 19}

Cognitive sophistication and asset-debt ratios

\begin{tabular}{cc}
\hline \hline Mean & -.0948 \\
Std. dev. & .1424 \\
$68 \%$ HPDI & {$[-.2425 .0386]$} \\
\hline \hline
\end{tabular}

Bayesian OLS regression of the variance of individual scores assigned to profiles in PGT (average across positive and negative net worth profiles) on CRT scores.

Random-walk Metropolis-Hastings sampling with 100000 MCMC sample size. Acceptance rate: 0.3933; average efficiency rate: 0.1187 .

Prior $N(0,1)$ on all model coefficients.

Values in parentheses are $68 \%$ highest posterior density intervals.

We carry out a second exercise, based on the different point estimates of the marginal propensities to consume of the two types of subjects in the experiment.

These imply that the MPC of unbiased subjects is $84.21 \%$ the MPC of biased subjects in the $€ 500$ case, while the ratio between the two MPCs is $86.95 \%$ in the $€ 5000$ case.

Under the hypothesis of constant relative risk aversion, the model yields the following ratio between the MPC (out of $y_{1}$ ) of the rational agent and that of the biased agent:

$$
M P C_{\text {ratio }}=\frac{1+\beta^{\frac{1}{\epsilon}}\left(1+r^{s}\right)^{\frac{1}{\epsilon}}(1+r)^{-1}}{1+\beta^{\frac{1}{\epsilon}}(1+r)^{\frac{1}{\epsilon}}(1+r)^{-1}}
$$

By means of the standard parametrization of $r, \beta$ and $\epsilon$ reported in Table 20, and given the definition of $r^{s}$ in Equation 11, we can find the combinations of $m_{2}^{*}$ and $g_{r}$ such that $M P C_{\text {ratio }} \in[84.21 \%, 86.95 \%]$. To this purpose, we randomly draw 1000 values of $m$ uniformly distributed in the interval $(0,1)$. Since $g_{r}=\gamma A / D$, where $\gamma \sim U(0,1)$, we also draw 1000 values for $\gamma$, and we assume an asset-debt ratio equal to 2.51. ${ }^{22}$ Hence, from Equation 11 we have in total 100000 values of the perceived interest rate $r^{s}$ and, consequently, of the MPC ratio in Equation 22.

Figure 5 highlights in black the values of the MPC ratio that fall within the interval $[.8421, .8695]$ found in the experiment. This corresponds to maximum values of $m_{2}^{*}$ and $\gamma$

\footnotetext{
${ }^{22}$ The value of the asset-debt ratio equals the average ratio of the profiles shown to subjects in PGT.
} 
Table 20

Parameters values

\begin{tabular}{cc}
\hline \hline$\beta$ & 0.99 \\
$\varepsilon$ & 0.8 \\
$r$ & 0.04 \\
$m$ & 1000 values from $U(0,1)$ \\
$A / D$ & 2.51 \\
$\gamma$ & 1000 values from $U(0,1)$ \\
\hline \hline
\end{tabular}

equal to 0.91 and 2.51 respectively, as well as to minimum values equal to 0 for $m_{2}^{*}$ and 0.27 for $\gamma$. Hence, the figure shows that lower values of optimal attention allow to obtain the MPC ratio that ranges in the values observed in the experiment, only as long as the prior generated by System 1 - i.e. the default value of the interest rate - does not differ substantially from the true value. This indeed guarantees a perceived value of the interest rate, $r^{s}$, such that $M P C_{\text {ratio }} \in[84.21 \%, 86.95 \%]$.

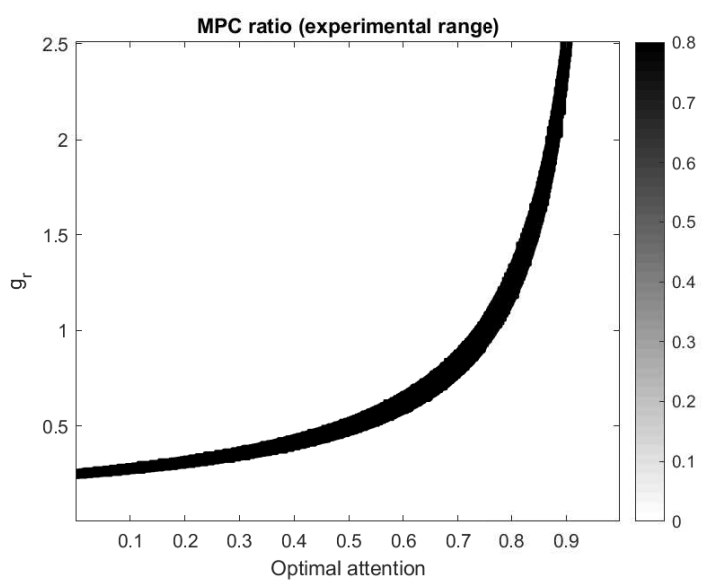

Figure 5: Pairs of $m$ and $g_{r}$ corresponding to values of the MPC ratio in the interval [.8421,.8695] (in black).

\section{Conclusion}

By means of a laboratory experiment, we test the existence of different levels of perceived wealth associated with financially equivalent balance sheet profiles in a controlled environment. We find that the majority of subjects give different evaluations of balance sheet profiles with equal net worth, but different levels of assets and debt, even though these are non-interest bearing, risk-free and unaffected by price variations. This points to a violation of standard consumer theory and the fungibility of money: balance sheet composition matters for the perception of wealth. In particular, the prevailing emerging pattern is the leverage bias, which consists in a strong preference for profiles that have greater asset-debt ratios. Our findings in the first two tasks of the experiment indeed suggest that perceived wealth, for a given net worth, is an increasing function of the asset-debt ratio.

We explore different explanations for our result. We find that risk preferences and financial education and experience do not predict the presence of the leverage bias. Our result is however related to the differences in the level of cognitive sophistication and attention between biased and unbiased subjects. In particular, subjects with the leverage bias perform significantly 
worse in CRT compared to unbiased subjects. This suggests that the misperception of wealth is related to a predominance of System 1 type of thinking, which is automatic and makes little use of attentional resources (Kahneman, 2003a,b; Kihlstrom, 1987; Moritz et al., 2014; Toplak et al., 2014). By means of a survey on hypothetical debt and consumption choices, we also find that the leverage bias predicts individual attitudes towards debt, consumption behavior and individual saving types. Biased subjects generally identify themselves as the type of person that spends and enjoys the present, as well as being more comfortable with the idea of buying goods by borrowing. We also find that subjects with the leverage bias are more likely to take on debt for consumption, and more prone to increase spending out of unexpected gains under financial profiles that are associated with greater perceived wealth, while unbiased subjects seem more debt averse and generally indifferent to the composition of the balance sheet for debt and consumption decisions. In addition, our results indicate that biased subjects are more likely to borrow in case of a financial emergency that leaves them unable to finance due payments.

We finally build a simple model that provides a structural interpretation of our results. This is a two-period optimal consumption choice model that compares the behavior of a standard rational agent - representing unbiased subjects in our experiment - with a behavioral agent à la Gabaix $(2014,2019)$ - representing biased subjects. Based on our experimental findings, this agent has a wrong perception of wealth due to low cognitive sophistication and greater inattention. We show that the model can account for biased subjects' greater tendency to spend and rely on debt for consumption, compared to rational unbiased subjects. In line with our experimental results, the model also predicts a larger marginal propensity to consume for the biased agent and, therefore, lower consumption smoothing.

This work has different implications for policy. Our experimental results suggest that removing potential sources of frictions may not be sufficient to prevent the formation of biases that, through the erroneous perception of wealth, impact spending and borrowing behavior. Similarly, greater financial literacy or experience with basic financial instruments do not have any impact on wealth misperception and the associated consumption and debt decisions. Further research should investigate whether the correlation between low cognitive abilities and the greater probability of being biased may be related to the presence of cognitive load that temporarily limits the attentional resources available at the time of perception formation and decision-making. The presence of a cognitive load indeed creates a tax on the brain that produces limited bandwidth and attention, and it is associated with poorer decisions also at the financial level (Deck and Jahedi, 2015; Mullainathan and Shafir, 2014; Shah et al., 2012).

\section{References}

Abeler, J. and Marklein, F. (2017). Fungibility, Labels, and Consumption. Journal of the European Economic Association, 15(1):99-127.

Agarwal, S. and Mazumder, B. (2013). Cognitive abilities and household financial decision making. American Economic Journal: Applied Economics, 5(1):193-207.

Agarwal, S. and Qian, W. (2014). Consumption and debt response to unanticipated income shocks: Evidence from a natural experiment in Singapore? American Economic Review, 104(12):3841-3884.

Allred, S., Duffy, S., and Smith, J. (2016). Cognitive load and strategic sophistication. Journal of Economic Behavior and Organization, 125:162-178.

Andersen, S., Campbell, J. Y., Nielsen, K. M., and Ramadorai, T. (2014). Inattention and Inertia in Household Finance: Evidence from the Danish Mortgage Market. SSRN Electronic Journal. 
Andersson, O., Holm, H. J., Tyran, J. R., and Wengström, E. (2016). Risk Aversion Relates To Cognitive Ability: Preferences or Noise? Journal of the European Economic Association, 14(5):1129-1154.

Aschersleben, G., Hofer, T., and Jovanovic, B. (2008). The link between infant attention to goal-directed action and later theory of mind abilities. Developmental Science, 11(6):862-868.

Attanasio, O. P., Guiso, L., and Jappelli, T. (2002). The demand for money, financial innovation, and the welfare cost of inflation: An analysis with household data. Journal of Political Economy, 110(2):317-351.

Banks, J. and Oldfield, Z. (2007). Understanding pensions: Cognitive function, numerical ability and retirement saving. Fiscal Studies, 28(2):143-170.

Barrett, L. F., Tugade, M. M., and Engle, R. W. (2004). Individual differences in working memory capacity and dual-process theories of the mind. Psychological Bulletin, 130(4):553573.

Ben-Shakhar, G. and Sheffer, L. (2001). The relationship between the ability to divide attention and standard measures of general cognitive abilities. Intelligence, 29(4):293-306.

Bénabou, R. and Tirole, J. (2006). Belief in a just world and redistributive politics. Quarterly Journal of Economics, 121(2):699-746.

Bertrand, M. and Morse, A. (2011). Information Disclosure, Cognitive Biases, and Payday Borrowing. Journal of Finance, 66(6):1865-1893.

Beshears, J., Choi, J. J., Laibson, D., and Madrian, B. C. (2018). Behavioral Household Finance. In Bernheim, B. D., DellaVigna, S., and Laibson, D., editors, Handbook of Behavioral Economics: Foundations and Applications 1, pages 177-276. Elsevier, Amsterdam.

Bianchi, M. (2018). Financial Literacy and Portfolio Dynamics. Journal of Finance, 73(2):831859.

Black, S. E., Devereux, P. J., Lundborg, P., and Majlesi, K. (2018). Learning to Take Risks? the Effect of Education on Risk-Taking in Financial Markets. Review of Finance, 22(3):951-975.

Bosch-Rosa, C., Meissner, T., and Bosch-Domènech, A. (2018). Cognitive bubbles. Experimental Economics, pages 132-153.

Camarda, C. G., Eilers, P. H. C., and Gampe, J. (2017). Modelling general patterns of digit preference. Journal of the Royal Statistical Society: Series C (Applied Statistics), 66(5):893918.

Chambers, J. R., Swan, L. K., and Heesacker, M. (2014). Better Off Than We Know: Distorted Perceptions of Incomes and Income Inequality in America. Psychological Science, 25(2):613618.

Chen, D. L., Schonger, M., and Wickens, C. (2016). oTree-An open-source platform for laboratory, online, and field experiments. Journal of Behavioral and Experimental Finance, 9:88-97.

Chien, Y. I. and Devaney, S. A. (2001). The effects of credit attitude and socioeconomic factors on credit card and installment debt. Journal of Consumer Affairs, 35(1):162-179.

Cruces, G., Perez-Truglia, R., and Tetaz, M. (2013). Biased perceptions of income distribution and preferences for redistribution: Evidence from a survey experiment. Journal of Public Economics, 98:100-112. 
Dawtry, R. J., Sutton, R. M., and Sibley, C. G. (2015). Why wealthier people think people are wealthier, and why it matters: From social sampling to attitudes to redistribution. Psychological Science, 26(9):1389-1400.

de Langhe, B. and Puntoni, S. (2015). Bang for the Buck: Gain-Loss Ratio as a Driver of Judgment and Choice. Management Science, 61(5):1137-1163.

Deaton, A. (2008). Life-cycle models of consumption: Is the evidence consistent with the theory? In Advances in Econometrics, pages 121-148.

Deck, C. and Jahedi, S. (2015). The effect of cognitive load on economic decision making: A survey and new experiments. European Economic Review, 78:97-119.

Dohmen, T., Falk, A., Huffman, D., and Sunde, U. (2010). Are Risk Aversion and Impatience Related to Cognitive Ability? American Economic Review, 100(3):1238-1260.

Dukas, R. (2004). Causes and consequences of limited attention. In Brain, Behavior and Evolution, volume 63, pages 197-210.

Fehr, E. and Tyran, J. R. (2014). Does money illusion matter? Reply. American Economic Review, 104(3):1063-1071.

Fisher, I. (1928). The Money Illusion. New York: Adelphi Company.

Frederick, S. (2005). Cognitive Reflection and Decision Making. Journal of Economic Perspectives, 19(4):25-42.

Fuster, A., Kaplan, G., and Zafar, B. (2018). What would you do with 500? spending responses to gains, losses, news and loans. NBER Working Paper, 24386.

Gabaix, X. (2014). A sparsity-based model of bounded rationality. Quarterly Journal of Economics, 129(4):1661-1710.

Gabaix, X. (2019). Behavioral Inattention. In Bernheim, B. D., DellaVigna, S., and Laibson, D., editors, Handbook of Behavioral Economics, volume 2, chapter 4, pages 261-343.

Gasiorowska, A. (2014). The relationship between objective and subjective wealth is moderated by financial control and mediated by money anxiety. Journal of Economic Psychology, 43:6474 .

Gerardi, K., Goette, L., and Meier, S. (2013). Numerical ability predicts mortgage default. Proceedings of the National Academy of Sciences of the United States of America, 110(28):1126711271.

Gorbachev, O. (2011). Did household consumption become more volatile? American Economic Review, 101(5):2248-2270.

Guzman, M. and Stiglitz, J. E. (2016a). Pseudo-wealth and consumption fluctuations. NBER Working Paper, No. 22838.

Guzman, M. and Stiglitz, J. E. (2016b). A Theory of Pseudo-Wealth, pages 21-33. Palgrave Macmillan UK, London.

Hastings, J. S. and Shapiro, J. M. (2013). Fungibility and consumer choice: Evidence from commodity price shocks. Quarterly Journal of Economics, 128(4):1449-1498.

Hastings, W. K. (1970). Monte carlo sampling methods using Markov chains and their applications. Biometrika, 57(1):97-109. 
Hauser, O. P. and Norton, M. I. (2017). (Mis)perceptions of inequality. Current Opinion in Psychology, 18:21-25.

Holt, C. A. and Laury, S. K. (2002). Risk aversion and incentive effects. American Economic Review, 92(5):1644-1655.

Jappelli, T. and Pistaferri, L. (2010). The Consumption Response to Income Changes. Annual Review of Economics, 2(1):479-506.

Johnson, D. S., Parker, J. A., and Souleles, N. S. (2006). Household expenditure and the income tax rebates of 2001 .

Kahneman, D. (1973). Attention and effort. Prentice-Hall, Englewood Cliffs, NJ.

Kahneman, D. (2003a). A perspective on judgment and choice: mapping bounded rationality. American Psychologist, 58(9), 697-720. American Psychologist, 58(9):687-720.

Kahneman, D. (2003b). Maps of bounded rationality: Psychology for behavioral economics. American Economic Review, 93(5):1449-1475.

Kahneman, D. (2011). Thinking Fast and Slow. Farrar, Straus and Giroux.

Kahneman, D. and Tversky, A. (1979). Prospect Theory: An Analysis of Decision under Risk. Econometrica, 47(2):263-292.

Khaw, M. W., Li, Z., and Woodford, M. (2017). Risk Aversion as a Perceptual Bias. NBER Working Paper, 23294.

Khaw, M. W., Li, Z., and Woodford, M. (2019). Cognitive Imprecision and Small-Stakes Risk Aversion. NBER Working Paper, 24978.

Kihlstrom, J. F. (1987). The cognitive unconscious. Science, 237(4821):1445-1452.

Kooreman, P. (2000). The labeling effect of a child benefit system. American Economic Review, 90(3):571-583.

Loughnan, S., Kuppens, P., Allik, J., Balazs, K., de Lemus, S., Dumont, K., Gargurevich, R., Hidegkuti, I., Leidner, B., Matos, L., Park, J., Realo, A., Shi, J., Sojo, V. E., yue Tong, Y., Vaes, J., Verduyn, P., Yeung, V., and Haslam, N. (2011). Economic inequality is linked to biased self-perception. Psychological Science, 22(10):1254-1258.

Lusardi, A. and Tufano, P. (2015). Debt literacy, financial experiences, and overindebtedness. Journal of Pension Economics and Finance, 14(4):332-368.

Metropolis, N., Rosenbluth, A. W., Rosenbluth, M. N., Teller, A. H., and Teller, E. (1953). Equation of state calculations by fast computing machines. The Journal of Chemical Physics, 21(6):1087-1092.

Miao, J. and Xie, D. (2013). Economic growth under money illusion. Journal of Economic Dynamics and Control, 37(1):84-103.

Modigliani, F. and Miller, M. H. (1958). The Cost of Capital, Corporation Finance and the Theory of Investment. American Economic Review, 68(3):261 - 297.

Moritz, B., Siemsen, E., and Kremer, M. (2014). Judgmental forecasting: Cognitive reflection and decision speed. Production and Operations Management, 23(7):1146-1160.

Mullainathan, S. and Shafir, E. (2014). Scarcity: The True Cost of Not Having Enough. Penguin Books. 
Norton, M. I. and Ariely, D. (2011). Building a better America-one wealth quintile at a time. Perspectives on Psychological Science, 6(1):9-12.

Parker, J. A. (2017). Why don’t households smooth consumption? Evidence from a $\$ 25$ million experiment. American Economic Journal: Macroeconomics, 9(4):153-183.

Parker, J. A. and Souleles, N. S. (2017). Reported Preference vs. Revealed Preference: Evidence from the Propensity to Spend Tax Rebates. NBER Working Paper, 23290.

Parker, J. A., Souleles, N. S., Johnson, D. S., and McClelland, R. (2013). Consumer spending and the economic stimulus payments of 2008. American Economic Review, 103(6):2530-2553.

Ravallion, M. and Lokshin, M. (2002). Self-rated economic welfare in Russia. European Economic Review, 46(8):1453-1473.

Shafir, E., Diamond, P., and Tversky, A. (1997). Money Illusion. the Quarterly Journal of Economics, 112(2):341-374.

Shah, A. K., Mullainathan, S., and Shafir, E. (2012). Some consequences of having too little. Science, 338(6107):682-685.

Sicherman, N., Loewenstein, G., Seppi, D. J., and Utkus, S. P. (2016). Financial Attention. Review of Financial Studies, 29(4):863-897.

Simon, H. A. (1978). Rationality as Process and as Product of Thought. American Economic Review, 68(2):1-16.

Sims, C. A. (2003). Implications of rational inattention. Journal of Monetary Economics, 50(3):665-690.

Stango, V. and Zinman, J. (2009). Exponential Growth Bias and Household Finance. The Journal of Finance, 64(6):2807-2849.

Stango, V. and Zinman, J. (2014). Limited and varying consumer attention: Evidence from shocks to the salience of bank overdraft fees. Review of Financial Studies, 27(4):990-1030.

Stanovich, K. E. and West, R. F. (2003). Individual differences in reasoning: Implications for the rationality debate? Behavioral and Brain Sciences, 23:645-726.

Sussman, A. B. (2017). Valence in context: Asymmetric reactions to realized gains and losses. Journal of Experimental Psychology: General, 146(3):376-394.

Sussman, A. B. and O'Brien, R. L. (2016). Knowing When to Spend: Unintended Financial Consequences of Earmarking to Encourage Savings. Journal of Marketing Research, 53(5):790-803.

Sussman, A. B. and Shafir, E. (2012). On assets and debt in the psychology of perceived wealth. Psychological science, 23(1):101-8.

Taylor, M. P. (2013). Bias and brains: Risk aversion and cognitive ability across real and hypothetical settings. Journal of Risk and Uncertainty, 46(3):299-320.

Thaler, R. H. (1990). Anomalies: Saving, Fungibility, and Mental Accounts. Journal of Economic Perspectives, 4(1):193-205.

Thaler, R. H. (1999). Mental accounting matters. Journal of Behavioral Decision Making, 12(3):183-206. 
Toplak, M. E., West, R. F., and Stanovich, K. E. (2011). The Cognitive Reflection Test as a predictor of performance on heuristics-and-biases tasks. Memory and Cognition, 39(7):12751289 .

Toplak, M. E., West, R. F., and Stanovich, K. E. (2014). Assessing miserly information processing: An expansion of the Cognitive Reflection Test. Thinking and Reasoning, 20(2):147-168.

Tversky, A. and Kahneman, D. (1981). The framing of decisions and the psychology of choice. Science, 211(4481):453-458.

van Rooij, M., Lusardi, A., and Alessie, R. (2011). Financial literacy and stock market participation. Journal of Financial Economics, 101(2):449-472. 


\section{Appendices}

\section{A - Experiment instructions}

The experiment was carried out in Italian. Instructions were displayed on the computer screen before the beginning of each task. The following pages report an English translation. 


\section{WELCOME}

Please take your time to read the instructions very carefully: there is no benefit to moving fast through the experiment.

Today's experiment is made of five different parts: Task 1, Task 2, Task 3, Task 4 and Task 5. In each part, you will have to answer some questions.

If you pay attention and complete your tasks, you may earn a considerable amount of money in each part. At the end of the experiment you will be paid a participation fee of $5 €$ plus the amount won in each of the three parts.

In the next page you will be presented with the instructions of Task 1. After completing Task 1, you will access the other tasks and the corresponding instructions.

During the experiment you are not allowed to talk to the other participants, use cell phones or start any other programs on the computer.

The neglect of these rules will lead to the immediate exclusion from the experiment and all payments.

If you have any questions, please raise your hand.

Please proceed to the next page when you are ready to start. 


\section{INTRODUCTION}

The financial profile of an individual is generally represented by his assets, liabilities and net worth.

Assets refers to the money that represents a person's wealth.

Liabilities refers to debt, that is the money a person has to give back.

Net worth refers to the difference between assets and liabilities and it may be either positive (if assets are greater than liabilities) or negative (in the opposite case).

For example, the following table represents the financial profile of Mr. Rossi:

\section{Sig. Rossi}

\begin{tabular}{cc}
\hline Attività & $8.000 €$ \\
Passività & $2.000 €$ \\
\hline Saldo & $6.000 €$
\end{tabular}

In this example, Mr. Rossi has $8000 €$ worth of assets and $2000 €$ worth of liabilities. His net worth is therefore equal to $6000 €$.

YOUR TASK.

In the next pages you will be shown 12 pairs of financial profiles, described by assets, liabilities and net worth, in line with what mentioned above.

For each pair, you will have to choose the profile that you consider financially better off.

Be careful: once you confirm your choice, you will not be able to modify it.

In making your decisions, keep in mind the following information:

1. All values of assets and liabilities shown are certain, that is they do not change over time;

2. The two profiles in each pair correspond to people who earn the same monthly income;

3. Both individuals in each pair can obtain loans under the same conditions, if necessary;

4. All assets and liabilities are non-interest bearing: both individuals in each pair do not pay any interest on their debt and do not receive any interest on their assets.

Please proceed to the next page when you are ready to start. 
Pairs shown to participants (sorted randomly for each participant):

\begin{tabular}{cc}
\multicolumn{2}{c}{ Mr. A } \\
\hline Attività & $1.200 €$ \\
Passività & $200 €$ \\
\hline Saldo & $1.000 €$ \\
\multicolumn{2}{c}{ Mr. A } \\
\hline Attività & $44.200 €$ \\
Passività & $32.000 €$ \\
\hline Saldo & $12.200 €$ \\
\multicolumn{2}{c}{ Mr. A } \\
\hline Attività & $50.000 €$ \\
Passività & $800 €$ \\
\hline Saldo & $49.200 €$ \\
& \\
\hline Attività & $32.000 €$ \\
Passività & $7.350 €$ \\
\hline Saldo & $24.650 €$
\end{tabular}

\begin{tabular}{cc}
\multicolumn{2}{c}{ Mr. B } \\
\hline Attività & $15.000 €$ \\
Passività & $14.000 €$ \\
\hline Saldo & $1.000 €$
\end{tabular}

Mr. A

\begin{tabular}{cc}
\multicolumn{2}{c}{ Mr. A } \\
\hline Attività & $135.000 €$ \\
Passività & $7.000 €$ \\
\hline Saldo & $128.000 €$
\end{tabular}

\begin{tabular}{cc}
\multicolumn{2}{c}{ Mr. A } \\
\hline Attività & $500 €$ \\
Passività & $21.000 €$ \\
\hline Saldo & $-20.500 €$
\end{tabular}

\begin{tabular}{cc}
\multicolumn{2}{c}{ Mr. B } \\
\hline Attività & $12.800 €$ \\
Passività & $600 €$ \\
\hline Saldo & $12.200 €$
\end{tabular}

\begin{tabular}{cc}
\multicolumn{2}{c}{ Mr. B } \\
\cline { 2 - 2 } Attività & $69.500 €$ \\
Passività & $20.300 €$ \\
\hline Saldo & $49.200 €$
\end{tabular}


Mr. A

\begin{tabular}{cc}
\hline Attività & $18.000 €$ \\
Passività & $48.000 €$ \\
\hline Saldo & $-30.000 €$ \\
\multicolumn{2}{c}{ Mr A } \\
\hline Attività & $1.300 €$ \\
Passività \\
\hline Saldo & $1.000 €$ \\
\multicolumn{2}{c}{ Mr A } \\
\hline Attività \\
Passività & $33.000 €$ \\
\hline Saldo & $11.200 €$
\end{tabular}

Mr. B

\begin{tabular}{cc}
\hline Attività & $400 €$ \\
Passività & $30.400 €$ \\
\hline Saldo & $-30.000 €$ \\
\multicolumn{2}{c}{ Mr B } \\
\hline Attività & $17.000 €$ \\
Passività & \\
\hline Saldo & $1.000 €$
\end{tabular}

Mr B

\begin{tabular}{cc}
\hline Attività & \\
Passività & $12.500 €$ \\
\hline Saldo & $11.200 €$
\end{tabular}




\section{INTRODUCTION}

This task maintains the information provided in the previous task. So, the meaning of assets, liabilities and net worth remains the same as before. For the sake of clarity, we summarize them again here:

Assets refers to the money that represents a person's wealth. Liabilities refers to debt, that is the money a person has to give back. Net worth refers to the difference between assets and liabilities and it may be either positive (if assets are greater than liabilities) or negative (in the opposite case).

YOUR TASK

In this task you will be shown 10 financial profiles given by assets, liabilities and net worth. Next to each profile, you will find a pointer on a bar, like this one:

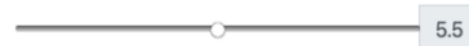

Your task consists in evaluating the financial soundness of each profile by assigning a grade between 1 and 10. To do so, move the pointer along the bar corresponding to each profile.

In range of grades, 1 indicates that your evaluation is extremely negative (you think the profile is not at all financially solid); 10 indicates that your evaluation is extremely positive (you think the profile is very solid from a financial perspective).

If you consider any profiles as financially equivalent, please assign them any same grade.

In making your decisions, keep in mind the following information:

1. All values of assets and liabilities shown are certain, that is they do not change over time;

2. The two profiles in each pair correspond to people who earn the same monthly income;

3. Both individuals in each pair can obtain loans under the same conditions, if necessary;

4. All assets and liabilities are non-interest bearing: both individuals in each pair do not pay any interest on their debt and do not receive any interest on their assets.

Please proceed to the next page when you are ready to start. 


\section{TASK 3}

Task 3 consists of some questions of differing difficulty. Try to answer as many of them as possible.

You have 2 minutes and 30 seconds of time for each question.

Think carefully about the answer you choose: For each correct answer in this task we will pay you $1 €$.

Please proceed to the next page when you are ready to start.

QUESTIONS shown to participants (one per page, sequentially):

- A bat and a ball cost 1.10 Euros. The bat costs 1 Euro more than the ball. How much does the ball cost?

- It takes 5 machines 5 minutes to make 5 widgets. How long would it take 100 machines to make 100 widgets?

- In a lake, there is a patch of lily pads. Every day, the patch doubles in size. If it takes 48 days for the patch to cover the entire lake, how long would it take for the patch to cover half of the lake? 
This task is composed of a sequence of 10 decisions. For each decision, you have to choose between Option A and Option B, which are shown in the table below (the table will be shown also in the next pages, so you don't have to learn it by heart).

\begin{tabular}{|c|c|c|}
\hline Decision & Option A & Option B \\
\hline 1 & $\begin{array}{c}\text { Win } 2,00 € \text { with probability } 1 \text { over } 10 \\
\text { OR } \\
\text { Win } 1,60 € \text { with probability } 9 \text { over } 10\end{array}$ & $\begin{array}{c}\text { Win } 3,85 € \text { with probability } 1 \text { over } 10 \\
\text { OR } \\
\text { Win } 0,10 € \text { with probability } 9 \text { over } 10\end{array}$ \\
\hline 2 & $\begin{array}{c}\text { Win } 2,00 € \text { with probability } 2 \text { over } 10 \\
\text { OR } \\
\text { Win } 1,60 € \text { with probability } 8 \text { over } 10\end{array}$ & $\begin{array}{l}\text { Win } 3,85 € \text { with probability } 2 \text { over } 10 \\
\text { OR } \\
\text { Win } 0,10 € \text { with probability } 8 \text { over } 10\end{array}$ \\
\hline 3 & $\begin{array}{l}\text { Win } 2,00 € \text { with probability } 3 \text { over } 10 \\
\text { OR } \\
\text { Win } 1,60 € \text { with probability } 7 \text { over } 10\end{array}$ & $\begin{array}{c}\text { Win } 3,85 € \text { with probability } 3 \text { over } 10 \\
\text { OR } \\
\text { Win } 0,10 € \text { with probability } 7 \text { over } 10\end{array}$ \\
\hline 4 & $\begin{array}{c}\text { Win } 2,00 € \text { with probability } 4 \text { over } 10 \\
\text { OR } \\
\text { Win } 1,60 € \text { with probability } 6 \text { over } 10\end{array}$ & $\begin{array}{c}\text { Win } 3,85 € \text { with probability } 4 \text { over } 10 \\
\text { OR } \\
\text { Win } 0,10 € \text { with probability } 6 \text { over } 10\end{array}$ \\
\hline 5 & $\begin{array}{c}\text { Win } 2,00 € \text { with probability } 5 \text { over } 10 \\
\text { OR } \\
\text { Win } 1,60 € \text { with probability } 5 \text { over } 10\end{array}$ & $\begin{array}{c}\text { Win } 3,85 € \text { with probability } 5 \text { over } 10 \\
\text { OR } \\
\text { Win } 0,10 € \text { with probability } 5 \text { over } 10\end{array}$ \\
\hline 6 & $\begin{array}{c}\text { Win } 2,00 € \text { with probability } 6 \text { over } 10 \\
\text { OR } \\
\text { Win } 1,60 € \text { with probability } 4 \text { over } 10\end{array}$ & $\begin{array}{c}\text { Win } 3,85 € \text { with probability } 6 \text { over } 10 \\
\text { OR } \\
\text { Win } 0,10 € \text { with probability } 4 \text { over } 10\end{array}$ \\
\hline 7 & $\begin{array}{c}\text { Win } 2,00 € \text { with probability } 7 \text { over } 10 \\
\text { OR } \\
\text { Win } 1,60 € \text { with probability } 3 \text { over } 10\end{array}$ & $\begin{array}{c}\text { Win } 3,85 € \text { with probability } 7 \text { over } 10 \\
\text { OR } \\
\text { Win } 0,10 € \text { with probability } 3 \text { over } 10\end{array}$ \\
\hline 8 & $\begin{array}{c}\text { Win } 2,00 € \text { with probability } 8 \text { over } 10 \\
\text { OR } \\
\text { Win } 1,60 € \text { with probability } 2 \text { over } 10\end{array}$ & $\begin{array}{c}\text { Win } 3,85 € \text { with probability } 8 \text { over } 10 \\
\text { OR } \\
\text { Win } 0,10 € \text { with probability } 2 \text { over } 10\end{array}$ \\
\hline 9 & $\begin{array}{c}\text { Win } 2,00 € \text { with probability } 9 \text { over } 10 \\
\text { OR } \\
\text { Win } 1,60 € \text { with probability } 1 \text { over } 10\end{array}$ & $\begin{array}{c}\text { Win } 3,85 € \text { with probability } 9 \text { over } 10 \\
\text { OR } \\
\text { Win } 0,10 € \text { with probability } 1 \text { over } 10\end{array}$ \\
\hline 10 & $\begin{array}{l}\text { Win } 2,00 € \text { with probability } 10 \text { over } 10 \\
\text { OR } \\
\text { Win } 1,60 € \text { with probability } 0 \text { over } 10\end{array}$ & $\begin{array}{c}\text { Win } 3,85 € \text { with probability } 10 \text { over } 10 \\
\text { OR } \\
\text { Win } 0,10 € \text { with probability } 0 \text { over } 10\end{array}$ \\
\hline
\end{tabular}

After making all the 10 decisions, your computer will choose one of them randomly. Each of the 10 decisions has an equal probability of being chosen.

Based on the selected decision, your computer will then determine the amount of your pay. To this purpose, your computer will throw a 10-sided dice and play the associated lottery.

For example, imagine your computer selects decision number 1. Your computer will then throw the 10-sided dice: if you have chosen option A, you will win $2 €$ if the dice shows the side " 1 ", or $1.6 €$ if the dice shows one of the other 9 sides; if instead you have chosen option $B$, you will win $3.85 €$ if the dice shows the side " 1 ", or $0.10 €$ if the dice shows one of the other 9 sides.

Hence, even if you make 10 decisions, only one of them will determine your payment in this task. Clearly, as already pointed out, each decision has an equal probability of being chosen for your payment but you have no possibility to know in advance which of the decisions is going to be selected.

Please proceed to the next page when you are ready. 


\section{TASK 5}

The last task consists of a short survey of about 20 questions. Please take the necessary amount of time to answer accurately.

How old are you?

What is your gender?

A: female, male

How many people live in your family?

A: $1,2,3,4,5+$

What is your parents' education level?

A: None of my parents holds a degree; Only one of my parents holds a degree; Both of my parents hold a degree

Do you have any financial education?

A: Yes, No

Have you ever participated in experiments like this one before?

A: Yes, No

Do you have at least one credit or debit card?

A: Yes; No

In general, do you prefer to spend money and enjoy it today or save for the future?

A: Spend and enjoy it today; Save for the future

In general, do you think it is a good idea or a bad idea for people to buy things by borrowing?

A: Good idea; Good in some ways, bad in others; Bad idea

If tomorrow you experienced a financial emergency that left you unable to pay all of your bills, how would you deal with it?

A: Borrow money; Spend out of savings; Postpone payments; Cut back; Other

Imagine that your TV is getting old and you want to change it with a new flat screen HD smart TV. However, since you don't have the money to purchase it outright, you would need to borrow 450 $€$ in order to buy it. In which case would you be more likely to borrow to buy the new TV? A: Mr. A (high profile); Mr. B (low profile); I would borrow in either case; I would not borrow in either case (Asked twice, once with positive NW, once with negative NW)

Consider a hypothetical situation in which you unexpectedly receive a one-time payment of $500 €$ Euros. What would you do over the next month?

A: I would spend more than if I hadn't received the 500€; I would spend the same as if I hadn't received the $500 €$; I would spend less than if I hadn't received the $500 €$. 
CONDITIONAL: You indicated that you would increase your spending over the next month following the receipt of the $500 €$ payment. How much more would you spend than if you hadn't received the $500 €$ ?

Consider a hypothetical situation in which you unexpectedly receive a one-time payment of 5000 $€$ Euros. What would you do over the next month?

A: I would spend more than if I hadn't received the 5000€; I would spend the same as if I hadn't received the $5000 €$; I would spend less than if I hadn't received the $5000 €$.

CONDITIONAL: You indicated that you would increase your spending over the next month following the receipt of the $5000 €$ payment. How much more would you spend than if you hadn't received the $5000 €$ ?

Consider again a hypothetical situation in which you unexpectedly receive a one-time payment of $500 €$ today. In which case would you be more likely to increase your expenses?

A: Mr. A (high profile); Mr. B (low profile); I would increase my expenses in either case; I would not increase my expenses in either case 


\section{B - Further tables}

Table 21 reports the posterior mean (i.e. logit coefficients) used for the computation of predicted probabilities in Table 2.

Table 21

Posterior mean for predicted probabilities in Table 2

\begin{tabular}{ccccc}
\hline \hline & Unbiased & Leverage bias & Other bias & Partial bias \\
\hline Posterior mean & -1.4336 & -.0013 & -2.4976 & -2.3239 \\
Std. dev. & .304 & .994 & .449 & .422 \\
$68 \%$ HPDI & {$[-1.7111-1.1102]$} & {$[-.95631 .0159]$} & {$[-2.8752-1.9885]$} & {$[-2.6882-1.8631]$} \\
\hline
\end{tabular}

Random-walk Metropolis-Hastings sampling with 100000 MCMC sample size; acceptance rate: .4398; average efficiency rate: .2195 .

Prior $N(0,1)$ on all model coefficients.

Values in parentheses are $68 \%$ highest posterior density intervals.

Table 22 reports the marginal effects from a series of Bayesian logistic regressions of a dummy for the leverage bias on four variables: CRT score, risk aversion, financial sophistication and financial education. In all regressions, we assume a $N(0,1)$ prior for model coefficients.

Table 22

Behavioral predictors of the leverage bias

\begin{tabular}{ccccc}
\hline \hline & $(1)$ & $(2)$ & $(3)$ & $(4)$ \\
\hline Risk aversion & .0149 & & & \\
$68 \%$ HPDI & {$[.0065 .0242]$} & & & \\
Financial sophistication & & .0660 & & \\
$68 \%$ HPDI & & {$[.0266 .1117]$} & & \\
Financial education & & & .0599 & \\
$68 \%$ HPDI & & {$[.0220 .0978]$} & -.0322 \\
CRT score & & & {$[-.0508-.0126]$} \\
$68 \%$ HPDI & No & No & No & No \\
Controls & 68 & 68 & 68 & 68 \\
Sample size & & & 68 \\
\hline \hline
\end{tabular}

Marginal effects from a Bayesian logistic regression of a dummy equal to 1 if the subject is biased on (1) CRT score, (2) number of safe choices in RISK, (3) a dummy equal to 1 if the subject has credit/debit card and (4) a dummy equal to 1 if the subject is financially educated.

Prior $N(0,1)$ on all model coefficients. Random-walk Metropolis-Hastings sampling with 100000 MCMC sample size.

Values in parentheses are $68 \%$ highest posterior density intervals.

Table 23 reports the marginal effects from a Bayesian logistic regression of general attitudes towards debt on a dummy for the leverage bias. We assume a $N(0,1)$ prior for the coefficient of the dummy.

Table 24 reports the marginal effects from a Bayesian multinomial logistic regression of responses to the hypothetical financial emergency on a dummy for the leverage bias. We assume a $N(0,1)$ prior for the coefficient of the dummy.

Table 25 reports the marginal effects from a Bayesian multinomial logistic regression of the likelihood to take on debt on a dummy for the leverage bias. We assume a $N(0,1)$ prior for the coefficient of the dummy. 
Table 23

Effect of the leverage bias on borrowing attitudes

\begin{tabular}{cccc}
\hline \hline & Averse & Seeker & Neutral \\
\hline Marginal effect & -.1843 & .2013 & -.0170 \\
$68 \%$ HPDI & {$[-.2309-.1280]$} & {$[.1581 .2533]$} & {$[-.0690 .0339]$} \\
Controls & No & No & No \\
Sample size & 68 & 68 & 68 \\
\hline \hline
\end{tabular}

Marginal effects from a Bayesian logistic regression of the measure of attitudes towards debt on a dummy equal to 1 if the subject is biased.

Prior $N(0,1)$ on all model coefficients. Random-walk Metropolis-Hastings sampling with 100000 MCMC sample size.

Values in parentheses are $68 \%$ highest posterior density intervals.

Table 24

Effect of the leverage bias on reactions to financial emergency

\begin{tabular}{cccccc}
\hline \hline & Borrow & Use savings & Postpone & Cut & Other \\
\hline Marginal effect & .2285 & -.1326 & -.0444 & -.0030 & -.0485 \\
$68 \%$ HPDI & {$[.1896 .2783]$} & {$[-.1750-.0775]$} & {$[-.0647-.0113]$} & {$[-.0532 .0586]$} & {$[-.0611-.0314]$} \\
Controls & No & No & No & No & No \\
Sample size & 68 & 68 & 68 & 68 & 68 \\
\hline \hline
\end{tabular}

Marginal effects from a Bayesian logistic regression of reactions to a financial emergency on a dummy equal to 1 if the subject is biased.

Prior $N(0,1)$ on all model coefficients. Random-walk Metropolis-Hastings sampling with 100000 MCMC sample size.

Values in parentheses are $68 \%$ highest posterior density intervals. 
Table 26 reports the marginal effects from a Bayesian logistic regression of a dummy for impatience on a dummy for the leverage bias. We assume a $N(0,1)$ prior for the coefficient of the dummy.

Table 25

Effect of the leverage bias on the likelihood to take on debt

\begin{tabular}{cccc}
\hline \hline & Group 1 & Group 2 & Group 3 \\
\hline Marginal effect & .4883 & -.4058 & -.0825 \\
68\% HPDI & {$[.4464 .5458]$} & {$[-.4683-.3450]$} & {$[-.1121-.0439]$} \\
Controls & No & No & No \\
Sample size & 68 & 68 & 68 \\
\hline \hline
\end{tabular}

Marginal effects from a Bayesian logistic regression of group belonging on a dummy equal to 1 if the subject is biased.

Prior $N(0,1)$ on all model coefficients. Random-walk Metropolis-Hastings sampling with 100000 MCMC sample size.

Values in parentheses are $68 \%$ highest posterior density intervals.

Table 26

Effect of the leverage bias on impatience

\begin{tabular}{lc}
\hline \hline Marginal effect & .3091 \\
$68 \%$ HPDI & {$[.2472 .3702]$} \\
Controls & No \\
Sample size & 68 \\
\hline \hline
\end{tabular}

Marginal effects from a Bayesian logistic regression of the measure of attitudes towards debt on a dummy equal to 1 if the subject is biased.

Prior $N(0,1)$ on all model coefficients. Random-walk Metropolis-Hastings sampling with 100000 MCMC sample size.

Values in parentheses are $68 \%$ highest posterior density intervals.

Table 27 reports the marginal effects from a Bayesian logistic regression of a dummy for impatience on a dummy for the leverage bias. We assume a $N(0,1)$ prior for the coefficient of the dummy.

Table 28 reports the marginal effects from a Bayesian logistic regression of a dummy for profile selection on a dummy for the leverage bias. We assume a $N(0,1)$ prior for the coefficient of the dummy.

Table 29 reports correlations among all predictors in our analysis. We include only the correlations whose absolute value is larger than 0.2 , as a rule of thumb. 
Table 27

Effect of the leverage bias on spending response

\begin{tabular}{cccc}
\hline \hline & Less & Same & More \\
\hline Marginal effect, $€ 500$ scenario & -.0470 & -.1482 & .1951 \\
$68 \%$ HPDI & {$[-.0616-.0150]$} & {$[-.2087-.0898]$} & {$[.1468 .2499]$} \\
& & & \\
Marginal effect, $€ 5000$ scenario & -.0710 & -.0704 & .1414 \\
$68 \%$ HPDI & {$[-.0900-.0370]$} & {$[-.1273-.0084]$} & {$[.0871 .1969]$} \\
& & & No \\
Controls & No & 68 & 68 \\
Sample size & 68 & 68 & No \\
\hline \hline
\end{tabular}

Marginal effects from a Bayesian logistic regression of spending responses on a dummy equal to 1 if the subject is biased.

Prior $N(0,1)$ on all model coefficients. Random-walk Metropolis-Hastings sampling with 100000 MCMC sample size.

Values in parentheses are $68 \%$ highest posterior density intervals.

Table 28

Effect of the leverage bias on increase in consumption

\begin{tabular}{cccc}
\hline \hline & $H R P$ & $L R P$ & Neutral \\
\hline Marginal effect & .3944 & -.1079 & -.2865 \\
$68 \%$ HPDI & {$[.3430 .4550]$} & {$[-.1391-.0566]$} & {$[-.3400-.2350]$} \\
Controls & No & No & No \\
Sample size & 68 & 68 & 68 \\
\hline \hline
\end{tabular}

Marginal effects from a Bayesian logistic regression of profile selection on a dummy equal to 1 if the subject is biased.

Prior $N(0,1)$ on all model coefficients. Random-walk Metropolis-Hastings sampling with 100000 MCMC sample size.

Values in parentheses are $68 \%$ highest posterior density intervals.

Table 29

Correlations

\begin{tabular}{|c|c|c|c|c|c|c|c|c|}
\hline & CRT score & Risk av. & Fin. soph. & Fin. edu. & Age & Gender & Fam. size & Fam. Edu. \\
\hline CRT score & 1 & & & & & & & \\
\hline Risk aversion & .2123 & 1 & & & & & & \\
\hline Financial sophistication & & & 1 & & & & & \\
\hline Financial education & & -.2195 & & 1 & & & & \\
\hline Age & & & & & 1 & & & \\
\hline Gender & & & & & & 1 & & \\
\hline Family size & & & & & & & 1 & \\
\hline Family education & & & -.3265 & & & & & 1 \\
\hline
\end{tabular}




\section{C - Proofs}

\section{Proof of Proposition 1.}

By combining the as-if intertemporal budget constraint (17) with condition 19, we can determine adjusted consumption in period one:

$$
c_{1}^{a}=\frac{y_{1}(1+r)-y_{1}^{s}\left(1+r^{s}\right)-\left(y_{2}^{\prime}-y_{2}\right)}{r-r^{s}}
$$

By substituting adjusted consumption in period 1 into the as-if intertemporal budget constraint, we can find the allocation of consumption in period two $\left(c_{2}^{a}\right)$, that is:

$$
c_{2}^{a}=\frac{\left(y_{1}^{s}-y_{1}\right)\left(1+r^{s}\right)(1+r)-y_{2}\left(1+r^{s}\right)+y_{2}^{\prime}(1+r)}{r-r^{s}}
$$

Since $r-r^{s}>0$, then $c_{1}^{a}>0$ when:

$$
y_{2}^{\prime}<y_{2}+y_{1}(1+r)-y_{1}^{s}\left(1+r^{s}\right)
$$

Moreover, the sparse agent is a borrower if her adjusted allocation is such that in period one she wants to consume more than her wealth, i.e. $c_{1}^{a}>y_{1}$. This is true if:

$$
y_{2}^{\prime}<y_{2}-\left(y_{1}^{s}-y_{1}\right)\left(1+r^{s}\right)
$$

Since $r>r^{s}$, then it follows that condition 26 implies condition 25: trivially, when the sparse agent borrows, her adjusted consumption in period 1 is also positive. So, ultimately, condition 26 guarantees both $c_{1}^{a}>0$ and that the agent is a borrower.

Adjusted consumption in period 2 is positive (i.e. $c_{2}^{a}>0$ ) if:

$$
y_{2}^{\prime}>y_{2} \frac{1+r^{s}}{1+r}-\left(y_{1}^{s}-y_{1}\right)\left(1+r^{s}\right)
$$

Combining conditions 26 and 27, we obtain

$$
y_{2} \frac{1+r^{s}}{1+r}-\left(y_{1}^{s}-y_{1}\right)\left(1+r^{s}\right)<y_{2}^{\prime}<y_{2}-\left(y_{1}^{s}-y_{1}\right)\left(1+r^{s}\right)
$$

This condition identifies the values of $y_{2}^{\prime}$ that guarantee that the biased agent is a borrower, while allowing for positive consumption in the second period.

\section{Proof of Proposition 2.}

Let us consider the true intertemporal budget constraint (Equation 4) and the as-if intertemporal budget constraint (Equation 15). We report them below for the reader convenience:

$$
\begin{aligned}
c_{1}+\frac{c_{2}}{1+r} & =y_{1}+\frac{y_{2}}{1+r} \\
c_{1}^{a}+\frac{c_{2}^{a}}{1+r^{s}} & =y_{1}^{s}+\frac{y_{2}^{\prime}}{1+r^{s}}
\end{aligned}
$$


By substituting for $c_{2}$ and $c_{2}^{a}$ from the Euler equations of the rational agent and the sparse agent (after adjusting consumption) and taking the difference at both sides at the optimum, we get:

$$
c_{1}^{a}-c_{1}^{*}=y_{1}^{s}-y_{1}+\frac{y_{2}^{\prime}}{1+r^{s}}-\frac{y_{2}}{1+r}-\frac{U^{\prime}-1\left[\frac{U_{c_{1}^{a}}^{\prime}}{\beta\left(1+r^{s}\right)}\right]}{1+r^{s}}+\frac{U^{\prime}-1\left[\frac{U_{c_{1}^{*}}^{\prime}}{\beta(1+r)}\right]}{1+r}
$$

Therefore, in order to compare $c_{1}^{a}$ and $c_{1}^{*}$, we assume a Constant Relative Risk Aversion (CRRA) utility function. ${ }^{23}$ Let us rewrite the optimization problem for the two agents.

$$
\max U\left(c_{1}, c_{2}\right)=\frac{c_{1}^{1-\varepsilon}}{1-\varepsilon}+\beta \frac{c_{2}^{1-\varepsilon}}{1-\varepsilon}
$$

s.t.

$$
c_{2}=\left(1+r^{s}\right)\left(y_{1}^{s}-c_{1}\right)+y_{2}
$$

Where $y_{1}=\hat{y}_{1}+N, N=A-D$.

The optimization problem yields the following Euler Equation:

$$
c_{1}^{*}=\left[\frac{1}{\beta(1+r)}\right]^{\frac{1}{\varepsilon}} c_{2}^{*}
$$

By making use of the Euler equation and the intertemporal budget constraint, we determine the rational agent's optimal allocation of consumption in both periods:

$$
\begin{aligned}
c_{1}^{*} & =\frac{1}{1+\beta^{\frac{1}{\varepsilon}}(1+r)^{\frac{1-\varepsilon}{\varepsilon}}}\left(y_{1}+\frac{y_{2}}{1+r}\right) \\
c_{2}^{*} & =\frac{[\beta(1+r)]^{\frac{1}{\varepsilon}}}{1+\beta^{\frac{1}{\varepsilon}}(1+r)^{\frac{1-\varepsilon}{\varepsilon}}}\left(y_{1}+\frac{y_{2}}{1+r}\right)
\end{aligned}
$$

The biased agent, solves the same problem but she uses perceived wealth $\left(w^{s}\right)$. Hence:

$$
\max U\left(c_{1}, c_{2}\right)=\frac{c_{1}^{1-\varepsilon}}{1-\varepsilon}+\beta \frac{c_{2}^{1-\varepsilon}}{1-\varepsilon}
$$

s.t.

$$
c_{2}=\left(1+r^{s}\right)\left(y_{1}^{s}-c_{1}\right)+y_{2}^{\prime}
$$

The solution to the optimal consumption choice problem above gives the following Euler equation:

$$
c_{1}^{s}=\left[\frac{1}{\beta\left(1+r^{s}\right)}\right]^{\frac{1}{\varepsilon}} c_{2}^{s}
$$

\footnotetext{
${ }^{23}$ Notice that such specification is in line with our experimental results. In fact, we do not find any correlation between the existence of the bias and agents' risk attitudes.
} 
By combining the Euler equation and the intertemporal budget constraint, we determine the optimal allocation of consumption in both periods for the sparse agent:

$$
\begin{aligned}
c_{1}^{s} & =\frac{1}{1+\beta^{\frac{1}{\varepsilon}}\left(1+r^{s}\right)^{\frac{1-\varepsilon}{\varepsilon}}}\left(y_{1}^{s}+\frac{y_{2}}{1+r^{s}}\right) \\
c_{2}^{s} & =\frac{\left[\beta\left(1+r^{s}\right)\right]^{\frac{1}{\varepsilon}}}{1+\beta^{\frac{1}{\varepsilon}}\left(1+r^{s}\right)^{\frac{1-\varepsilon}{\varepsilon}}}\left(y_{1}^{s}+\frac{y_{2}}{1+r^{s}}\right)
\end{aligned}
$$

However, the desired optimal allocation for the sparse agent is not feasible, as it exceeds the agent's available resources. The agent, therefore, is smart enough to adjust her allocation of consumption:

$$
\begin{aligned}
c_{1}^{a} & =\frac{1}{1+\beta^{\frac{1}{\varepsilon}}\left(1+r^{s}\right)^{\frac{1-\varepsilon}{\varepsilon}}}\left(y_{1}^{s}+\frac{y_{2}^{\prime}}{1+r^{s}}\right) \\
c_{2}^{a} & =\frac{\left[\beta\left(1+r^{s}\right)\right]^{\frac{1}{\varepsilon}}}{1+\beta^{\frac{1}{\varepsilon}}\left(1+r^{s}\right)^{\frac{1-\varepsilon}{\varepsilon}}}\left(y_{1}^{s}+\frac{y_{2}^{\prime}}{1+r^{s}}\right)
\end{aligned}
$$

As described in Condition 19, the adjusted allocation of consumption corresponds to the value of $y_{2}^{\prime}$ that, given her sparse perception of wealth, allows to exhausts the true budget constraint. In other words, $y_{2}^{\prime}$ guarantees that the budget constraint is hit under the true levels of the interest rate $(r)$ and income in period two $\left(y_{2}\right)$ :

$$
c_{1}^{a}\left(y_{1}^{s}, r^{s}, y_{2}^{\prime}\right)+\frac{c_{2}^{a}\left(y_{1}^{s}, r^{s}, y_{2}^{\prime}\right)}{1+r}=y_{1}+\frac{y_{2}}{1+r}
$$

Given optimal consumption for both agents determined above, we determine the condition such that the adjusted consumption of the biased agent in period 1 is greater than the optimal consumption of the rational agent in the same period:

$$
c_{1}^{a}>c_{1}^{*} \Longleftrightarrow y_{2}^{\prime}>\frac{\left(1+r^{s}\right)\left[1+\beta^{\frac{1}{\varepsilon}}\left(1+r^{s}\right)^{\frac{1-\varepsilon}{\varepsilon}}\right]}{1+\beta^{\frac{1}{\varepsilon}}(1+r)^{\frac{1-\varepsilon}{\varepsilon}}}\left(y_{1}+\frac{y_{2}}{1+r}\right)-\left(1+r^{s}\right) y_{1}^{s}
$$

In order to find the value of $y_{2}^{\prime}$ that guarantees that condition 39 is satisfied, we substitute for $c_{1}^{a}$ and $c_{2}^{a}$ into 38:

$$
y_{2}^{\prime}=\frac{(1+r)\left[1+r^{s}+\beta^{\frac{1}{\epsilon}}\left(1+r^{s}\right)^{\frac{1}{\epsilon}}\right]}{1+r+\beta^{\frac{1}{\epsilon}}\left(1+r^{s}\right)^{\frac{1}{\epsilon}}}\left(y_{1}+\frac{y_{2}}{1+r}\right)-\left(1+r^{s}\right) y_{1}^{s}
$$

Given the value of $y_{2}^{\prime}$ in Equation 40, it is trivial to show that, since $r>r^{s}$, the condition in Equation 39 is always satisfied for any $\varepsilon>0$. Hence, $c_{1}^{a}>c_{1}^{*}$ always.

Summing up, by assuming a CRRA utility function, we show that the adjusted optimal consumption choice made by the biased agent leads her to consume a greater share of her wealth in period 1, compared to the rational agent, under the condition in Equation 39.

We finally compute the derivative of optimal consumption of the two types of agents in period 1 with respect to $y_{1}$ : 


$$
\begin{aligned}
\frac{\partial c_{1}^{a}}{\partial y_{1}} & =\frac{1}{1+\beta^{\frac{1}{\epsilon}} \frac{\left(1+r^{s}\right)^{\frac{1}{\epsilon}}}{1+r}} \\
\frac{\partial c_{1}}{\partial y_{1}} & =\frac{1}{1+\beta^{\frac{1}{\epsilon}} \frac{(1+r)^{\frac{1}{\epsilon}}}{1+r}}
\end{aligned}
$$

Proposition A: Consider the derivatives in Equations 41 and 42. It is trivial to show that the biased agent has a greater propensity to consume out of positive income shocks in period 1 compared to the unbiased agent, as long as $r>r^{s}$, which is true by assumption.

\section{D $\quad$ - The case $w^{s}<w$}

As pointed out in Section 3.2.1, perceived wealth can be either higher or smaller than actual wealth. This appendix shows the computations when $w^{s}<w$. In Equations 8 and 9, if $g_{y_{1}}=-\psi A / D$, with $\log \psi \sim N(0, \eta)$, where $\eta$ is a finite variance, and $g_{r}=-\gamma A / D$, with $\gamma \sim U(0,1)$ then $y_{1}^{d}<y_{1}$ and $r^{d}>r$ such that $w^{s}<w$.

Consider $c_{1}^{a}$ and $c_{2}^{a}$ as defined in Equations 36 and 37. If $r^{s}>r$ and $y_{1}>y_{1}^{s}$ such that $w^{s}<w$, it is trivial to show that the adjusted agent is a borrower, i.e. $c_{1}^{a}>y_{1}$ iff:

$$
y_{2}^{\prime}<y_{2}+\left(y_{1}-y_{1}^{s}\right)\left(1+r^{s}\right)
$$

Moroever her consumtpion in period 2 is positive, i.e. $c_{2}^{a}>0$ iff:

$$
y_{2}^{\prime}<y_{2} \frac{1+r^{s}}{1+r}+\left(y_{1}-y_{1}^{s}\right)\left(1+r^{s}\right)
$$

Given the results above Proposition 1. in the paper in this scenario holds if:

$$
y_{2}^{\prime}<y_{2}+\left(y_{1}-y_{1}^{s}\right)\left(1+r^{s}\right)
$$

In fact, since $r^{s}>r$ and $y_{1}>y_{1}^{s}$, the condition in Equation 43 guarantees that also the condition in Equation 44 is satisfied. Hence, Equation 45 indeed guarantees that the adjusted agent is a borrower $\left(c_{1}^{a}>y_{1}\right)$ and her consumption in period two is positive $\left(c_{2}^{a}>0\right)$.

Moreover given the value of $y_{2}^{\prime}$ in Equation 40, it is trivial to show that, since $r^{s}>r$, the condition in Equation 39 is never satisfied. Hence, $c_{1}^{a}<c_{1}^{*}$ always, which in turn implies that the biased agent has a smaller propensity to consume out of positive income shocks in period 1 compared to the unbiased agent. 


\title{
IMFS WORKING PAPER SERIES
}

\author{
Recent Issues
}

\begin{tabular}{|c|c|c|}
\hline 134 / 2019 & Helmut Siekmann & $\begin{array}{l}\text { The Asset Purchase Programmes of the } \\
\text { ESCB - an interdisciplinary evaluation }\end{array}$ \\
\hline $133 / 2019$ & $\begin{array}{l}\text { Josefine Quast } \\
\text { Maik H. Wolters }\end{array}$ & $\begin{array}{l}\text { Reliable Real-time Output Gap Estimates } \\
\text { Based on a Modified Hamilton Filter }\end{array}$ \\
\hline 132 / 2019 & $\begin{array}{l}\text { Galina Potjagailo } \\
\text { Maik Wolters }\end{array}$ & Global Financial Cycles since 1880 \\
\hline $131 / 2019$ & $\begin{array}{l}\text { Philipp Lieberknecht } \\
\text { Volker Wieland }\end{array}$ & $\begin{array}{l}\text { On the Macroeconomic and Fiscal Effects } \\
\text { of the Tax Cuts and Jobs Act }\end{array}$ \\
\hline $130 / 2019$ & Eduard Hofert & Regulating Virtual Currencies \\
\hline 129 / 2018 & $\begin{array}{l}\text { Olga Goldfayn-Frank } \\
\text { Johannes Wohlfart }\end{array}$ & $\begin{array}{l}\text { How Do Consumers Adapt to a New } \\
\text { Environment in their Economic } \\
\text { Forecasting? Evidence from the German } \\
\text { Reunification }\end{array}$ \\
\hline 128 / 2018 & $\begin{array}{l}\text { Christopher Roth } \\
\text { Johannes Wohlfart }\end{array}$ & $\begin{array}{l}\text { How Do Expectations About the } \\
\text { Macroeconomy Affect Personal } \\
\text { Expectations and Behavior? }\end{array}$ \\
\hline 127 / 2018 & $\begin{array}{l}\text { Michael Haliassos } \\
\text { Thomas Jansson } \\
\text { Yigitcan Karabulut }\end{array}$ & Financial Literacy Externalities \\
\hline $126 / 2018$ & Felix Strobel & $\begin{array}{l}\text { The Government Spending Multiplier, } \\
\text { Fiscal Stress and the Zero Lower Bound }\end{array}$ \\
\hline 125 / 2018 & $\begin{array}{l}\text { Alexander Meyer-Gohde } \\
\text { Daniel Neuhoff }\end{array}$ & $\begin{array}{l}\text { Generalized Exogenous Processes in } \\
\text { DSGE: A Bayesian Approach }\end{array}$ \\
\hline 124 / 2018 & Athanasios Orphanides & $\begin{array}{l}\text { The Boundaries of Central Bank } \\
\text { Independence: Lessons from } \\
\text { Unconventional Times }\end{array}$ \\
\hline $123 / 2018$ & $\begin{array}{l}\text { Karl-Heinz Tödter } \\
\text { Gerhard Ziebarth }\end{array}$ & $\begin{array}{l}\text { Zinsen, Effektivpreise und Lebenskosten - } \\
\text { Ein Beitrag zur Konstruktion eines } \\
\text { intertemporalen Preisindex }\end{array}$ \\
\hline 122 / 2018 & Helmut Siekmann & Legal Tender in the Euro Area \\
\hline $121 / 2018$ & Maik H. Wolters & $\begin{array}{l}\text { How the Baby Boomers' Retirement Wave } \\
\text { Distorts Model-Based Output Gap } \\
\text { Estimates }\end{array}$ \\
\hline $120 / 2017$ & Helmut Siekmann & $\begin{array}{l}\text { Die Einstandspflicht der Bundesrepublik } \\
\text { Deutschland für die Deutsche Bundesbank } \\
\text { und die Europäische Zentralbank }\end{array}$ \\
\hline
\end{tabular}


119 / 2017 Gregor Boehl

118 / $2017 \quad$ Gregor Boehl Thomas Fischer

117 / 2017 Tobias H. Tröger

116 / 2017 Tobias H. Tröger

$115 / 2017$

114 / 2017

$113 / 2017$

112 / 2017

$111 / 2017$

$110 / 2017$

$109 / 2016$

108 / $2016 \quad$ Helmut Siekmann

107 / 2016

$106 / 2016$

$105 / 2016$

$104 / 2016$

Jorge Quintana
Guenter W. Beck Volker Wieland

Michael Binder

Philipp Lieberknecht

Volker Wieland

Mewael F. Tesfaselassie

Maik Wolters

Gerhard Rösl

Franz Seitz

Karl-Heinz Tödter

Jinhyuk Yoo

Robert C. M. Beyer

Volker Wieland

Helmut Siekmann

Volker Wieland

Elena Afanasyeva

Meguy Kuete

Jinhyuk Yoo

Helmut Siekmann

Athanasios Orphanides

Helmut Siekmann
Monetary Policy and Speculative Stock Markets

Can Taxation Predict US Top-Wealth Share Dynamics?

Why MREL Won't Help Much

Too Complex to Work - A Critical

Assessment of the Bail-in Tool under the

European Bank Recovery and Resolution

Regime

How to Normalize Monetary Policy in the Euro Area

Model Uncertainty in Macroeconomics: On the Implications of Financial Frictions

The Impact of Growth on Unemployment in a Low vs. a High Inflation Environment

Doing away with cash? The welfare costs of abolishing cash

Capital Injection to Banks versus Debt Relief to Households

Instability, imprecision and inconsistent use of equilibrium real interest rate estimates

Replacing or Supplementing the Euro in Member States whose Currency is the Euro

Restricting the Use of Cash in the European Monetary Union

New Methods for Macro-Financial Model Comparison and Policy Analysis

Konstruktionsfehler bei der Einlagensicherung auf EU-Ebene

Fiscal Implications of Central Bank Balance Sheet Policies

Preis- und Finanzstabilität: der Primat der Politik, der rechtliche Rahmen und das „ökonomische Gesetz" 